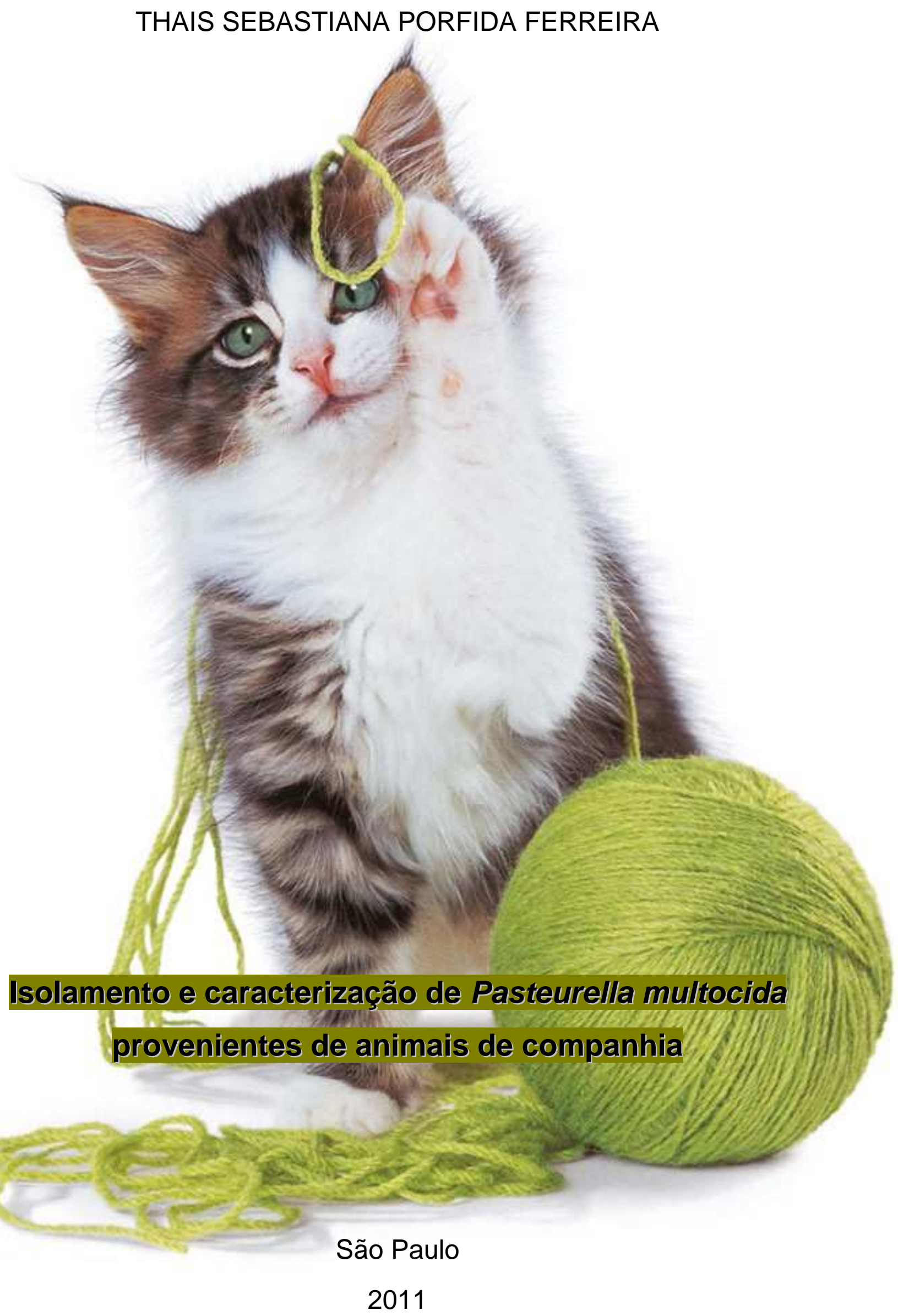




\title{
Isolamento e caracterização de Pasteurella multocida provenientes de animais de companhia
}

\author{
Tese apresentada ao Programa de Pós- \\ Graduação em Epidemiologia Experimental \\ Aplicada às Zoonoses da Faculdade de \\ Medicina Veterinária e Zootecnia da \\ Universidade de São Paulo para obtenção do \\ título de Doutor em Ciências \\ Departamento: \\ Medicina Veterinária Preventiva e Saúde \\ Animal \\ Área de concentração: \\ Epidemiologia Experimental e Aplicada às \\ Zoonoses \\ Orientadora: \\ Profa. Dra. Andrea Micke Moreno
}

São Paulo 
Autorizo a reprodução parcial ou total desta obra, para fins acadêmicos, desde que citada a fonte.

DADOS INTERNACIONAIS DE CATALOGAÇÃO-NA-PUBLICAÇÃO

(Biblioteca Virginie Buff D’Ápice da Faculdade de Medicina Veterinária e Zootecnia da Universidade de São Paulo)

Ferreira, Thais Sebastiana Porfida

Isolamento e caracterização de Pasteurella multocida provenientes de animais de companhia / Thais Sebastiana Porfida Ferreira. -- 2011.

$62 \mathrm{f}$ : : il.

Tese (Doutorado) - Universidade de São Paulo. Faculdade de Medicina Veterinária e Zootecnia. Departamento de Medicina Veterinária Preventiva e Saúde Animal, São Paulo, 2011.

Programa de Pós-Graduação: Epidemiologia Experimental Aplicada às Zoonoses. Área de concentração: Epidemiologia Experimental Aplicada às Zoonoses.

Orientador: Profa. Dra. Andrea Micke Moreno.

1. Pasteurella multocida. 2. Animais de companhia. 3. PCR. 4. PFGE. 5. Genes. I. Título. 


\section{FACULDADE DE MEDICINA VETERINÁRIA E ZOOTECNIA Comissão Bioética}

\section{CERTIFICADO}

Certificamos que o Projeto intitulado "Isolamento e caracterização de Pasteurella multocida provenientes de cães e gatos", protocolado sob o $\mathrm{n}^{\circ} 1450 / 2008$, utilizando 150 (cento e cinqüenta) cães e 150 (cento e cinqüenta) gatos, sob a responsabilidade da Profa. Dra. Andréa Micke Moreno, está de acordo com os princípios éticos de experimentação animal da Comissão de Bioética da Faculdade de Medicina Veterinária e Zootecnia da Universidade de São Paulo e foi aprovado em reunião de $01 / 10 / 08$.

We certify that the Research "Isolation and characterization of P. multocida from cats and dogs", utilizing 150 (one hundred fifty) dogs and 150 (one hundred fifty) cats, protocol number 1450/2008, under the responsibility Profa. Dra. Andréa Micke Moreno, agree with Ethical Principles in Animal Research adopted by Bioethic Commission of the School of Veterinary Medicine and Animal Science of University of São Paulo and was approved in the meeting of day 10/01/08.

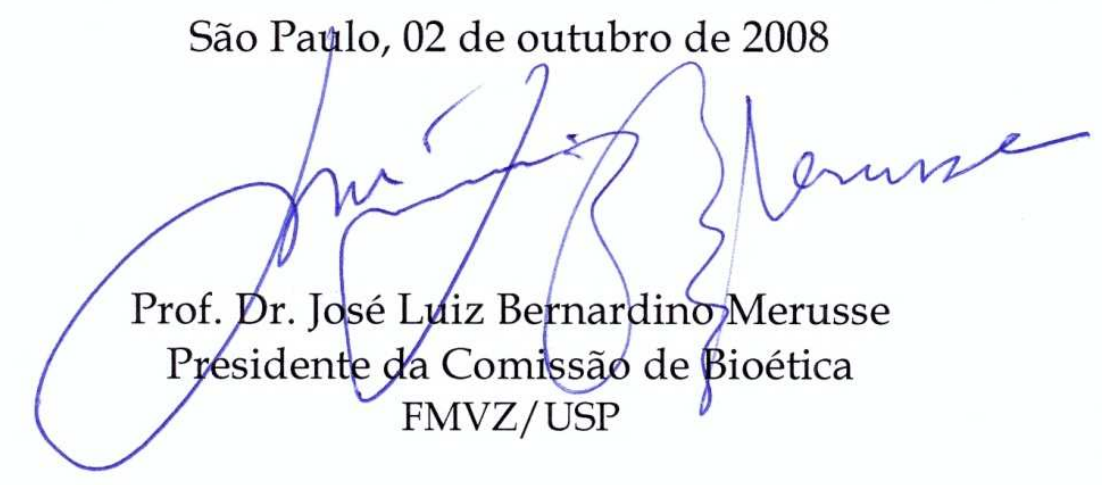




\section{FOLHA DE AVALIAÇÃO}

Nome: FERREIRA, Thais Sebastiana Porfida

Título: Isolamento e caracterização de Pasteurella multocida provenientes de animais de companhia.

Tese apresentada ao Programa de PósGraduação em Epidemiologia Experimental Aplicada às Zoonoses da Faculdade de Medicina Veterinária e Zootecnia da Universidade de São Paulo para a obtenção do título de Doutor em Ciências

Data:

\section{Banca Examinadora}

Profa. Dra. Instituição:

Assinatura: Julgamento:

Prof. Dr. Instituição:

Assinatura: Julgamento:

Prof. Dr. Instituição:

Assinatura: Julgamento:

Profa. Dra. Instituição:

Assinatura: Julgamento:

Profa. Dra. Instituição:

Assinatura: Julgamento: 


\section{AGRADECIMENTOS}

Aos mens pais por todo apoio e dedicação durante toda minha vida.

Ao meu esposo Renato pelo apoio e colaboração durante a reatização deste trabalho.

Aos meus queridos irmãos Julia e Francisco

Á Prof. Dr. Andrea Micke Moreno pela orientação, ajuda, apoí e oportunidades.

Aos amigos do Laboratório de Sanidade Suina e Virologia que me ajudaram na realização deste trabatho de uma forma ou de outra, Débora Gobbi, Marina Moreno, Sergio de Mello Novita Teixeira, Maria Roberta Felizardo, Renata Paixão, Danielle Raimundo, Cleise Ribeiro Gomes, Ana Paula Santos da Sílva, Alexandre Abelardo Sanches, Cristina Roman Amigo, Tania Alen Coutinho, Vasco Tútio de Moura Gomes, Jucélia de Jesus Pereira, Maria José Louro, Pedro Henrique Filsner.

Aos secretários do Departamento de Medicina Veterináría Preventiva e Saíde Animal, Maria Cristina Paick, Ana Virginia P. Almeida Prado, Danival Lopes Moreira e aos funcionários Sandra Sanches e Orlando B ispo de Souza.

A todos os animais que contribuiram para reatização deste trabalho

A Universidade de São Paulo, e a Faculdade de Medicina Veterináría e Zootecnia pelas condições de trabatho proporcionadas.

A Fundação de apoio a pesquisa do estado de São Pauto (FAPESP) pelo apoio financeiro -Bolsa processo 2007/08592-3.

Ao Sr. Henri Berghs da empresa Fairport Ltda pela autorização de uso do programa BioNumerics 6.6 (Applied Maths) para análise dos resultados obtidos neste estudo. 


\section{RESUMO}

FERREIRA, T. S. P. Isolamento e caracterização de Pasteurella Multocida provenientes de animais de companhia [Isolation and characterization of Pasteurella Multocida from pets]. 2011. 62 f. Tese (Doutorado em Ciências) Faculdade de Medicina Veterinária e Zootecnia, Universidade de São Paulo, São Paulo, 2011.

Pasteurella multocida é o agente causador de muitas doenças de importância econômica em medicina veterinária e tem sido descrita como um agente de alto potencial zoónotico. No Brasil, ao contrário do que se observa na literatura internacional, informações sobre a frequência deste agente em animais de companhia como cães, gatos e coelhos são inexistentes. O presente estudo teve como proposta isolar cepas de Pasteurella multocida a partir de cães, gatos e coelhos, avaliar a freqüência deste agente nestas espécies animais, caracterizar os isolados de acordo com o tipo capsular e genes codificadores de fatores de virulência através da reação em cadeia pela polimerase, avaliar o perfil de resistência a antimicrobianos dos isolados obtidos e caracterizar as amostras através da PFGE. Foram examinados 640 animais, sendo 191 gatos, 309 cães e 140 coelhos. Dentre os animais examinados $8,1 \%$ foram positivos para o isolamento de P. multocida, sendo $10,4 \%$ dos gatos, $0,9 \%$ dos cães e $20,7 \%$ dos coelhos avaliados. Dentre as 93 cepas selecionadas $22,5 \%$ foram sensíveis a todas as drogas testadas, $77,4 \%$ das cepas foram resistentes a pelo menos uma droga utilizada e 5,3\% foram apresentavam resistência a três ou mais drogas. Através da PFGE foram observados 39 pulsotipos com índice discriminatório igual a 0,97. Todos os genes codificadores de fatores de virulência foram detectados em pelo menos um isolado, sendo que nenhum destes esteve presente em 100\% das cepas avaliadas.

Palavras-chave: Pasteurella multocida. Animais de companhia. PCR. PFGE. Genes. 


\begin{abstract}
FERREIRA, T. S. P. Isolation and characterization of Pasteurella multocida from pets [Isolamento e caracterização de Pasteurella Multocida provenientes de animais de companhia]. 2011. 62 f. Tese (Doutorado em Ciências) - Faculdade de Medicina Veterinária e Zootecnia, Universidade de São Paulo, São Paulo, 2011.

Pasteurella multocida is the causative agent of many diseases of economic importance in veterinary medicine and has been described as an agent a high zoonotic potential. In Brazil, contrary to what is observed in the international literature, information about the frequency of this agent in animals such as dogs, cats and rabbits are nonexistent. This study proposes isolate strains of Pasteurella multocida from dogs, cats and rabbits, evaluate the frequency of this agent in these animal species, characterize the isolates according to the capsular type, and genes encoding virulence factors through the reaction polymerase chain, evaluate the antimicrobial resistance profiles of isolates and characterize the samples by PFGE. We examined 640 animals, 191 cats, 309 dogs and 140 rabbits. Among the animals examined were positive $8.1 \%$ for the isolation of $P$. multocida, and $10.4 \%$ of cats, dogs $0.9 \%$ and $20.7 \%$ of the rabbits studied. Among the 93 selected strains $22.5 \%$ were susceptible to all drugs tested, $77.4 \%$ of strains were resistant to at least one drug were used and $5.3 \%$ showed resistance to three or more drugs. Through PFGE were observed 39 pulsotipos discriminatory index equal to 0.97. All genes encoding virulence factors were detected in at least one isolated, none of which was present in $100 \%$ of the strains evaluated.
\end{abstract}

Keywords: Pasteurella multocida. Pets. PCR. PFGE. Genes. 


\section{SUMÁRIO}

1 INTRODUÇÃO 9

2 REVISÃO DE LITERATURA 11

2.1 INFECÇÕES EM PEQUENOS ANIMAIS $\mathbf{1 1}$

2.2 INFECÇÕES EM HUMANOS 12

2.3 CARACTERÍSTICAS DO AGENTE 13

2.4 FATORES DE VIRULÊNCIA 14

$\begin{array}{lll}2.4 .1 & \text { Toxinas } & 14\end{array}$

2.4.2 Proteínas externas de membrana (OMPs) 16

$\begin{array}{lll}2.4 .3 & \text { Enzimas } & 17\end{array}$

$\begin{array}{lll}2.4 .4 & \text { Fímbrias } & 18\end{array}$

2.4.5 Cápsula 19

2.5 IDENTIFICAÇÃO E CARACTERIZAÇÃO MOLECULAR DE P. multocida 20

2.5.1 Detecção e identificação através da PCR 21

2.5.2 Caracterização molecular de amostras de P. multocida 23

3 OBJETIVOS 26

4 MATERIAL E MÉTODO 27

4.1 AMOSTRAS

4.2 COLETA DAS AMOSTRAS

4.3 BACTERIOLÓGICO 28

4.4 PERFIL DE RESISTÊNCIA A ANTIMICROBIANOS $\mathbf{3 0}$

4.5 CARACTERIZAÇÃO GENOTÍPICA $\mathbf{3 1}$

4.5.1 Extração do DNA 31

4.5.2 Amplificação do DNA (PCR) 32

4.5.3 Detecção do produto de amplificação (amplicon) 35

4.6 ELETROFORESE EM CAMPO PULSADO (PFGE) 36

4.7 DETERMINAÇÃO DO ÍNDICE DISCRIMINATÓRIO (ID) $\mathbf{3 7}$

4.8 ANÁLISE ESTATÍSTICA DOS FRAGMENTOS AMPLIFICADOS $\mathbf{3 7}$

5 RESULTADOS 38

6 DISCUSSÃO 48

7 CONCLUSÃO $\quad 54$

REFERÊNCIAS 


\section{INTRODUÇÃO}

Pasteurella multocida é o agente causador de inúmeras doenças economicamente relevantes em todo o mundo, como a rinite atrófica em suínos, a septicemia hemorrágica em bovinos e búfalos, a broncopneumonia enzoótica em bovinos e ovelhas, a cólera aviária e infecções em coelhos (EWERS et al., 2006). Aves, bovinos, ovinos assim como ratos, cães e gatos também são considerados carreadores do agente (AVRIL et al,, 1990; DE JONG, 1999).

Infecções do trato respiratório superior por $P$. multocida são consideradas uma das doenças mais comuns em coelhos de estimação. Os sintomas incluem descarga nasal, espirros e conjuntivite (LANGAN et al, ,2000). Nos Estados Unidos mais de $50 \%$ dos coelhos adultos destinados à indústria morrem ou são eliminados da produção devido à infecção por $P$. multocida o que representa uma grande perda econômica (EL TAYEB et al., 2004).

No Brasil infecções em animais de produção pela $P$. multocida são muito frequentes como a rinite atrófica dos suínos que raramente ocasiona a morte dos animais, mas reduz consideravelmente o ganho de peso dos mesmos gerando perdas econômicas (BRITO et al., 1993; PIFFER ; CASTRO, 1993).

Cães e gatos são animais de companhia que fazem parte da vida moderna, sendo que seu convívio com os humanos tem se intensificado cada vez mais através dos anos. Desta forma os acidentes domésticos como as mordidas e arranhaduras se tornaram comuns. Talan et al. (1999) reporta que a cada ano milhares de Americanos são mordidos por animais e que $90 \%$ dessas mordidas são ocasionadas por cães e gatos, estes autores relatam que $28 \%$ a $80 \%$ dessas lesões infeccionam. 
Griego et al. (1995) relata que a $P$. multocida foi isolada em $50 \%$ a $80 \%$ dos casos de infecção cutânea em seres humanos causadas por mordidas de gatos e em $25 \%$ dos casos de infecção cutânea causadas por mordidas de cães, essas infecções podem resultar em inflamações locais e de linfonodos, podendo ocasionar complicações como abscessos e artrite séptica. Ocasionalmente, $P$. multocida pode estar envolvida em infecções sistêmicas como a meningite e a endocardite, especialmente em indivíduos imunossuprimidos (BISGAARD, 1993; FREDERIKSEN, 1993; EWERS et al., 2004). Amostras toxigênicas de $P$. multocida têm sido isoladas de humanos com amidalite, sinusite, rinite, pleurite, apendicite e septicemia, reforçando o potencial zoónotico do agente (NIELSEN; FREDERIKSEN, 1990; TURNQUIST, 1995). Atualmente no Brasil estudos voltados para a epidemiologia e caracterização da P. multocida são escassos (BRITO et al. 1993; PIFFER; CASTRO, 1993). 


\section{REVISÃO DE LITERATURA}

\subsection{INFECÇÕES EM PEQUENOS ANIMAIS}

Em cães e gatos, predominantemente nos gatos, a $P$. multocida é um componente comum da microbiota oral e do trato respiratório superior (LIU et al., 2003). Bactérias que colonizam a orofaringe são frequentemente aspiradas, e podem estar presentes no trato respiratório inferior por um intervalo de tempo desconhecido, ocasionando ou complicando infecções respiratórias. Em cães e gatos estas infecções bacterianas apresentam como sinais clínicos dispnéia, febre, tosse, corrimento nasal mucopurulento ou seroso, letargia, anorexia e perda de peso (TILLEY; SMITH, 2003).

Os gatos por apresentarem hábitos de caça mais conservados que os cães e por serem criados muitas vezes de maneira mais livre apresentam lesões de pele ocasionadas por mordidas e arranhaduras devido às brigas, essas lesões quando infectadas pela $P$. multocida podem dar origem a abscessos subcutâneos chegando a casos de septicemia em indivíduos imunodeprimidos (LOVE et al,, 2000).

Em coelhos a $P$. multocida é um patógeno comum frequentemente associado às doenças do trato respiratório superior. Os coelhos podem ser contaminados imediatamente após seu nascimento e a colonização pelo agente aumenta até os cinco meses de idade, fato que não impede os coelhos adultos de serem infectados (EL TAYEB et al., 2004). A pasteurelose nestes animais pode se apresentar como 
rinite com descarga nasal purulenta, pneumonia, otite média, piometra, orquites, abscessos, conjuntivites e septicemia (ROUGIER et al., 2006).

\subsection{INFECÇÕES EM HUMANOS}

Em humanos a $P$. multocida é um agente frequentemente encontrado em abscessos cutâneos, desenvolvidos após arranhaduras e mordidas de animais de companhia. As infecções podem ser adquiridas tanto através de cães como de gatos, sendo mais comuns àquelas adquiridas através do contato com gatos (LIU et al., 2003). Entretanto, em alguns casos, a infecção ocorre com indivíduos que possuem gatos como animais de companhia, sem que o mesmo tenha sido mordido ou arranhado pelo animal como, por exemplo, em um caso relatado por Liu et al. (2003) onde uma paciente com problemas renais tinha infecções recorrentes de urina devido a $P$. multocida.

Outro exemplo de infecção por P. multocida devido ao contato com gatos é dado por Cooke et a.I (2004) onde é relatado um caso de peritonite em um paciente renal grave que teve os cateteres de hemodiálise mordidos pelo seu gato de estimação.

Per et al. (2010) descrevem um caso de meningite e empiema subdural, subgaleal e epidural por P. multocida em um adolescente de 15 anos após contato com coelho de estimação. $O$ animal morreu subitamente e três dias depois o jovem começou a apresentar os sintomas da infecção. Os autores acreditam que o paciente se infectou ao coçar uma lesão de acne no couro cabeludo após manipular 
seu coelho. Neste caso, o adolescente não apresentava histórico de imussupressão nem de doenças anteriores.

Outro caso de infecção humana relacionada à mordida de coelhos é relatado por Silberfein et al. (2006) em um paciente que sofreu a infecção em um enxerto arterial, 28 meses após a cirurgia realizada para reparar um aneurisma de aorta abdominal. Em ambos os casos citados os pacientes tiveram recuperação total após terapia com antibióticos.

\subsection{CARACTERÍSTICAS DO AGENTE}

P. multocida pertence à família Pasteurellaceae que engloba os gêneros Pasteurella, Actinobacillus, Haemophillus e diversos outros com maior ou menor semelhança fenotípica e genotípica (CHRISTENSEN; BISGAARD, 1997).

O primeiro isolamento de uma bactéria do gênero Pasteurella ocorreu entre 1880 e 1881, sendo o nome Pasteurella, dado em homenagem a Louis Pasteur, que em 1887 isolou o agente em casos de cólera aviária de perus (MUTTERS et al., 1989; HUNT et al., 2000).

P. multocida é uma espécie heterogênea subdividida em três subespécies de acordo com os padrões de fermentação de carboidratos (MUTTERS et al., 1985). A P. multocida subsp. multocida que inclui a maior parte das amostras que causam infecção em humanos, bovinos, suínos, aves domésticas, gatos e coelhos, a $P$. multocida subsp. septica tem sido isolada em felinos e aves silvestres e a $P$. 
multocida subsp. gallicida tem sido descrita em aves e suínos (BLACKALL et al., 1997).

O agente é um cocobacilo ou bacilo curto com largura de 0,5 a $1 \mu \mathrm{m}$ e comprimento variando de 1 a $2 \mu \mathrm{m}$. Trata-se de uma bactéria Gram negativa, anaeróbia facultativa, imóvel, não hemolítica, produtora de indol, positiva para catalase e oxidase e negativa para urease. Em esfregaços frescos corados pelas técnicas de Giemsa ou Wrigth o organismo apresenta coloração bipolar (MUTTERS et al., 1989).

A espécie $P$. multocida apresenta cinco tipos capsulares, A, B, D, E e F. Além da classificação baseada nos componentes capsulares as amostras de $P$. multocida podem ser classificadas de acordo com os antígenos somáticos. Até o momento foram identificados 16 sorotipos somáticos (PIJOAN, 1999).

\subsection{FATORES DE VIRULÊNCIA}

\subsubsection{Toxinas}

Algumas amostras de $P$. multocida são capazes de produzir uma toxina protéica de 145 kDa, também conhecida como toxina dermonecrótica ou proteína Tox A (LICHTENSTEIGER et al., 1996). Esta toxina é termolábil, letal para 
camundongos quando administrada pela via intraperitoneal e causa lesão dermonecrótica em cobaio (DE JONG, 1980; DE JONG, 1999).

A toxina produzida pela $P$. multocida tem a habilidade de alterar a morfogênese de um tecido ou órgão. Esta toxina está diretamente envolvida nos casos de rinite atrófica em suínos. Nestes casos este processo se dá nos ossos turbinados nasais. As alterações nos ossos turbinados incluem um aumento no número de osteoclastos e uma progressiva degeneração dos osteoblastos (PEDERSEN ; ELLING, 1984). Estes tipos celulares juntos são responsáveis pelo processo de formação e remodelamento dos ossos. Os osteoblastos produzem as camadas de tecido ósseo e controlam a atividade dos osteoclastos. Os osteoclastos são responsáveis pela reabsorção do tecido ósseo, necessária para o remodelamento e crescimento ósseo. A toxina altera o equilíbrio entre a produção e reabsorção de tecido ósseo em favor da reabsorção. Como conseqüência o osso desaparece e eventualmente é substituído por células mesenquimais proliferadas (MULLAN; LAX,1998).

Estudos com diferentes linhagens de cultivos celulares mostraram que a toxina é um dos mais potentes fatores de crescimento conhecidos, sendo capaz sozinha de se ligar à célula, penetrar na mesma, alterar o metabolismo lipídico e ativar mecanismos de crescimento e divisão celular (STERNER-KOCK et al.,1995).

Não foi possível estabelecer a importância da toxina na patogenia de infecções pulmonares por $P$. multocida, embora alguns autores descrevam o isolamento de amostras toxigênicas a partir de pulmões de suínos. Amostras toxigênicas de $P$. multocida também são descritas causando doença em outras espécies como coelhos, caprinos, ovinos, aves, e bovinos (PIJOAN et al., 1984; IWAMATSU; SAWADA, 1988). 


\subsubsection{Proteínas externas de membrana (OMPs)}

As proteínas externas de membrana funcionam como barreiras seletivas que impedem a entrada de muitas moléculas tóxicas na célula, propriedade crucial para sobrevivência da bactéria em muitos ambientes. Ao mesmo tempo, estas proteínas exercem vários papeis na célula bacteriana, como absorção de nutrientes, transporte de moléculas para dentro e para fora da célula, além de interagirem com o tecido do hospedeiro e com o ambiente (HATFALUDI et a.I,2010).

O interesse crescente nas OMPs é devido a suas propriedades imunogênicas, o que faz destas proteínas candidatas potenciais a produção de vacinas (LU et al., 1991). No entanto, algumas destas proteínas também atuam diretamente como fatores de virulência (CHRISTENSEN; BISGAARD, 1997).

A necessidade de ferro e a capacidade de adquiri-lo in vivo têm sido descrita em diversas espécies, sendo os sistemas de captação de ferro considerados fatores de virulência (LEE et al., 1991). Proteínas externas de membrana de alto peso molecular têm sido especuladas como possíveis responsáveis pela captação de ferro em amostras de $P$. multocida, devido a sua expressão em meios de cultura com quantidades limitadas de ferro (ZHAO et al., 1995). A produção de quelantes de ferro de baixo peso molecular, semelhantes à sideróforos também tem sido cogitada (HU et al., 1986).

As OMPs de $P$. multocida também podem estar envolvidas na adesão à células alvo. Uma proteína de 35 kDa presente na cápsula de uma amostra de origem bovina do tipo A foi descrita como um possível fator de adesão. Anticorpos 
específicos contra esta proteína inibiram significantemente a adesão das OMPs a preparados de mucosa respiratória (LÜBKE et al., 1994).

Truscott e Hirsh (1988) observaram uma OMP com atividade antifagocítica em uma amostra de $P$. multocida aviária. Perus que receberam anticorpos específicos contra esta proteína de $50 \mathrm{kDa}$ foram protegidos quando desafiados com uma amostra virulenta de $P$. multocida.

\subsubsection{Enzimas}

Uma das enzimas mais estudadas em amostras de $P$. multocida é a neuraminidase. Apesar de esta enzima ser descrita em diferentes espécies de Pasteurella e outras espécies de bactérias, o papel desta enzima na virulência das amostras permanece obscuro (RIMLER; RHOADES, 1989). Com base em diversas investigações descobriu-se que todos os tipos capsulares e somáticos de $P$. multocida, com exceção do tipo capsular $F$, produzem uma neuraminidase que difere da produzida por outros microrganismos por apresentar alto peso molecular (CHRISTENSEN; BISGAARD, 1997).

A neuraminidase atua removendo o ácido siálico de glicoproteínas e glicolipídeos. Sugere-se que o efeito protetor de glicoproteínas salivares contra eventuais patógenos seja reduzido na presença de moléculas de neuraminidase. $\mathrm{O}$ mesmo efeito inibitório tem sido descrito para glicoproteínas séricas (principalmente transferrinas) de humanos, coelhos e bovinos (RIMLER; RHOADES, 1989). A 
relevância destes modelos para neuraminidase na patogenia da cólera aviária ou nas infecções em suínos permanece incerta (CHRISTENSEN; BISGAARD, 1997).

Outras enzimas têm sido descritas em amostras de $P$. multocida, mas sua importância na virulência do agente não é conhecida, dentre elas está a hialuronidase, a fosfatase alcalina, a esterase, a lipase, a leucina aminopeptidase, a fosfatase ácida, e a fosfohidrolase (CHRISTENSEN; BISGAARD, 1997).

\subsubsection{Fímbrias}

Fímbrias são apêndices bacterianos filamentosos de natureza protéica, visíveis através de microscopia eletrônica. A maioria das fímbrias bacterianas apresenta uma forte afinidade adesiva pela superfície de hemácias e outros tipos de células de animais, plantas e fungos (DUGUID et al., 1966; BOROWSKI, 2001).

O papel das fímbrias na virulência de diversas espécies é amplamente documentado, onde sua presença esta associada à patogenicidade e a colonização da célula hospedeira (DOUGHTY; RUFFOLO; ADLER, 2000). O isolamento de amostras fimbriadas de $P$. multocida tipo $A$ e tipo $D$ têm sido descritas por diferentes autores em aves, suínos e coelhos (GLORIOSO et al., 1982; PIFFER; CASTRO, 1993; TRIGO; PIJOAN, 1988).

Em isolados de P. multocida capazes de causar cólera aviária foi isolada e caracterizada a fimbria tipo 4 expressa pelo gene ptfA (DOUGHTY; RUFFOLO; 
ADLER, 2000). Estas fimbrias são compostas por repetidas subunidades protéicas de aproximadamente 15 a 20 KDa de massa, cuja a seqüência de aminoácidos terminais é altamente conservada (HATFALUDI et al., 2010).

fato da $P$. multocida freqüentemente abrigar 0 gene ptfA independentemente do tipo capsular e o fato deste tipo fimbrial ser altamente expresso em células do trato respiratório superior do hospedeiro tanto quanto in vitro, sugerem que as fimbrias do tipo 4 são candidatas potenciais para formulação de vacinas para pasteurelose. Entretanto o seqüenciamento do gene ptfA de vários isolados de $P$. multocida mostraram alto grau de variação o que pode limitar o potencial de uma vacina baseada em antígenos fimbriais (EWERS et al., 2006).

\subsubsection{Cápsula}

A maioria das amostras de $P$. multocida possui uma cápsula similar à observada na superfície celular de várias espécies bacterianas. Esta cápsula é composta por polissacarídeos polianiônicos altamente hidratados, os quais são ligados covalentemente à superfície celular por moléculas de lipídio A (ROBERTS, 1996). Polissacarídeos são compostos por repetições de monossacarídeos unidos por ligações glicosídicas e formam um grupo muito diverso. Esta diversidade dos polissacarídeos capsulares é de significativa importância na patogênese das doenças sistêmicas (MOXON; KROLL, 1990). 
Carter (1955) foi o primeiro a relatar tipos capsulares específicos para $P$. multocida, posteriormente Later, Rimler e Rhodes (1989) descreveram os cinco tipos distintos de cápsulas (A, B, D, E e F). Em suínos os tipos capsulares $A$ e $D$ de $P$. multocida costumam estar associados a pneumonias e a rinite atrófica, em bovinos o tipo capsular A esta associado a quadros de pneumonia e o tipo B a quadros de septicemia hemorrágica (ARUMUGAM et al, 2011). O tipo capsular A também é encontrado em isolados de doenças respiratórias de coelhos (EL TAYEB; MORISHITA; ANGRICK, 2004).

A cápsula de $P$. multocida tem sido relacionada à virulência, pois amostras com cápsula apresentam maior resistência à fagocitose e ao efeito bactericida do complemento (SNIPES et al., 1986). Mutantes acapsulares de uma série de microrganismos apresentam virulência reduzida (BOYCE et al., 2000). No caso de $P$. multocida do tipo A, cepas acapsulares, se mostraram avirulentas em galinhas e incapazes de se estabelecerem no tecido muscular destas (HARPER; BOYCE; ADLER, 2006).

\subsection{IDENTIFICAÇÃO E CARACTERIZAÇÃO MOLECULAR DE P. multocida}

Desde o primeiro isolamento em 1881, a detecção, a identificação e a caracterização de $P$. multocida limitou-se a habilidade de cultivar e purificar o microrganismo em laboratório. O agente purificado era então classificado de acordo com suas características fenotípicas, como morfologia da colônia, padrão de 
fermentação de carboidratos, como L-arabinose, dulcitol, D-glucose, D-lactose, maltose, D-manitol, D-sorbitol, D-sacarose, D-trealose e D- xilose, e de acordo com suas propriedades sorológicas (DZIVA et al., 2008). No entanto, condições relativas ao cultivo do agente podem influenciar na expressão destes atributos diminuindo a estabilidade e a repetitividade dos métodos fenotípicos usados para caracterização das amostras (MATSUMOTO; STRAIN, 1993).

Recentemente, a identificação e a caracterização têm favorecido análises que refletem uma das propriedades mais fundamentais de um organismo, seu código genético. A caracterização genotípica possui uma versatilidade que ultrapassa as fronteiras da caracterização fenotípica por métodos tradicionais. A análise do ácido nucléico facilita a identificação e a rápida detecção de um microrganismo, a determinação de sua posição taxonômica e a investigação de relações genéticas intra-espécie. As diversas ferramentas de análise molecular têm sido amplamente aplicadas na identificação e caracterização de amostras de $P$. multocida (HUNT et al., 2000).

\subsubsection{Detecção e identificação através da PCR}

A utilização da PCR na caracterização de amostras de $P$. multocida foi descrita inicialmente em 1994 quando primers específicos para seqüência codificadora da proteína ToxA ou toxina dermonecrótica foram desenvolvidos por Nagai et al. (1994). Subseqüentemente, outros testes baseados na PCR foram 
descritos para detecção de amostras toxigênicas de $P$. multocida (KAMP et al., 1996; LICHTENSTEIGER et al., 1996). Dentre as reações descritas, a desenvolvida por Kamp et al. (1996) parece ser a mais sensível e efetiva para análise em larga escala de suabes nasais e de tonsila (HUNT et al., 2000).

Para identificação de amostras de $P$. multocida foram descritas algumas metodologias utilizando a PCR. Kasten et al. (1997), descreve a utilização de primers construídos para amplificar o gene psl de $P$. multocida, que codifica uma proteína similar a proteína P6 de Haemophilus influenzae e H. parainfluenzae. Townsend et al. (1998) desenvolveram PCR baseada na amplificação de uma seqüência denominada KMT1 específica para o agente e identificada através de hibridização subtrativa. Liu et al(2004) desenvolveu a PCR para detecção de $P$. multocida baseado em dois genes que supostamente regulam a transcrição (Pm 0762 e Pm 1231), sendo que estes genes parecem ser bastante específicos para $P$. multocida.

A partir da identificação de uma região no genoma bacteriano específica para amostras do tipo capsular B e posteriormente para o tipo A, foi possível identificar outras regiões codificadoras de proteínas da cápsula e desenvolver uma reação sob a forma de Multiplex (M-PCR) capaz de diferenciar as amostras de $P$. multocida tipo capsular A, B, D, E e F (TOWSEND et al., 2001). 


\subsubsection{Caracterização molecular de amostras de $\boldsymbol{P}$. multocida}

A caracterização fenotípica tem oferecido informações limitadas ou insuficientes para estudos epidemiológicos sobre amostras de $P$. multocida, principalmente quando se pretende realizar a diferenciação de cepas muito próximas (HUNT et al., 2000). A caracterização molecular como conhecemos hoje, oferece uma grande variedade de metodologias com especificidade, reprodutibilidade e poder discriminatório variáveis, muitas das quais têm sido descritas para diferenciar amostras de P. multocida fenotipicamente semelhantes com sucesso (HUNT et al., 2000).

Uma série de técnicas moleculares, incluindo análise por enzimas de restrição (restriction enzyme analysis - REA), amplificação randômica de regiões polimórficas (RAPD), ribotipagem, Polimorfismo do comprimento de fragmentos amplificados (AFLP) ou eletroforese em campo pulsado (PFGE), têm sido empregados em estudos epidemiológicos incluindo diferentes cepas de $P$. multocida os resultados indicam a existência de uma diversidade genômica considerável entre as cepas (SHIN et al., 2007).

A REA mostrou seu poder discriminatório quando isolados de suínos de $P$. multocida pertencentes ao mesmo sorotipo e tipo capsular foram diferenciados (HAREL et a.I, 1990) e também através da diferenciação de isolados de $P$. multocida causadores de rinite atrófica em suínos (GARDNER et al., 1994).

Informações significantes sobre a diversidade genética e estrutura populacional dentro dos isolados de $P$. multocida tem sido reveladas usando a 
ribotipagem. Este método tem caracterizado isolado de $P$. multocida de diversos países como Zimbábue, Tanzânia e Dinamarca (DZIVA et al., 2008).

O AFLP tem sido amplamente utilizado em estudos envolvendo a epidemiologia molecular de bactérias Gram negativas e Gram positivas (JANSSEN et al.,1996 ; VELAPPAN et al., 2001). Este método envolve a digestão do DNA bacteriano purificado com uma ou duas enzimas de restrição, seguido pela ligação dos fragmentos resultantes a um oligonucleotídeo adaptador de fita dupla, o qual é complementar a seqüência de bases do sítio de restrição. Os adaptadores são desenhados de forma que os sítios de restrição originais não sejam restabelecidos após a ligação, o que previne uma nova digestão enzimática. A amplificação seletiva destes fragmentos através da PCR é realizada utilizando-se pares de primers complementares à seqüências dos adaptadores. Os fragmentos de DNA amplificado pela PCR são analisados através da eletroforese em gel de agarose (MCLAUCHLIN et al., 2000). 


\section{Eletroforese em gel de campo pulsado}

A técnica de eletroforese em campo pulsado (Pulsed Field Gel Electrophoresis - PFGE) permite a separação de fragmentos de grandes dimensões. Nos métodos eletroforéticos convencionais, a separação de moléculas lineares de DNA (até $50 \mathrm{~kb}$ ) é efetuada em função da sua massa molecular, quando se aplica um campo elétrico unidirecional. O limite de resolução é atingido quando o raio de giro da molécula de DNA excede o tamanho médio do poro do gel forçando as moléculas a percorrerem um percurso sinuoso e a mobilidade eletroforética passa a ser independente da massa molecular. Na eletroforese em campo pulsado utilizamse campos elétricos alternados que forçam as moléculas de DNA a mudar continuamente de direção. Esta separação é baseada no maior tempo que moléculas de maior dimensão levam a mudar de direção de migração. Quanto maior for a molécula de DNA, maior é o tempo necessário para a sua reorientação e é nesta diferença dos tempos de reorientação que se baseia a separação das moléculas. O parâmetro crítico que afeta a separação das moléculas é o tempo do pulso, que é a duração da aplicação do campo elétrico numa dada direção (SCHWARTZ; CANTOR, 1984).

A PFGE por ser uma técnica de boa reprodutibilidade e com ótimo poder discriminatório tem sido muito utilizada e considerada a metodologia padrão (gold standard) na epidemiologia molecular (SCHWARTZ; CANTOR, 1984; GOERING, 1993). 


\section{OBJETIVOS}

- Avaliar a freqüência de Pasteurella multocida a partir de suabes da mucosa oral de gatos, cães e coelhos provenientes do Estado de São Paulo.

- Caracterizar os isolados de acordo com o tipo capsular, produção de toxina dermonecrótica e avaliar a ocorrência dos genes codificadores de fatores de virulência descritos.

- Avaliar o perfil de resistência a antimicrobianos dos isolados obtidos.

- Avaliar a similaridade dos isolados. 


\section{MATERIAL E MÉTODOS}

\subsection{AMOSTRAS}

Foi analisado um total de 309 amostras de suabes de gengiva de cães, 191 suabes de gengiva de gatos e 178 suabes nasais de coelhos. As amostras foram coletadas entre fevereiro de 2008 e abril de 2011 (Tabelas 1 e 2).

Os animais testados no presente estudos apresentaram diversas origens como proprietários particulares, organizações não governamentais de proteção (ONGS), canis, gatis e criatórios de coelhos, todos situados em municípios do Estado de São Paulo.

\subsection{COLETA DAS AMOSTRAS}

As amostras foram coletadas com suabes estéreis acondicionados em meio de transporte de Stuart. Os tubos plásticos contendo os suabes foram mantidos sob refrigeração até o processamento, no período de 12 à 24h após a coleta (Figura 1). 


\subsection{BACTERIOLÓGICO}

O isolamento de P. multocida foi realizado segundo descrito por Knight et al, (1983). O suabe foi semeado em ágar sangue de cavalo contendo fosfato de clindamicina $(5 \mathrm{mg} / \mathrm{l})$, sulfato de gentamicina $(0,75 \mathrm{mg} / \mathrm{l})$ e telurito de potássio $(5 \mathrm{mg} / \mathrm{l})$ e incubado por $24 \mathrm{~h}$ a $37^{\circ} \mathrm{C}$ em aerobiose. As colônias suspeitas foram submetidas às provas bioquímicas como a produção de catalase, oxidase, descarboxilação da ornitina (DCO), atividade de urease e habilidade de produzir indol segundo descrito por Christensen et al. (2005).

A reação em cadeia pela polimerase foi utilizada para confirmação da espécie (TOWSEND et al., 1998). As cepas identificadas como $P$. multocida foram estocadas a -86ํㅡ até o momento de realização da PFGE. 


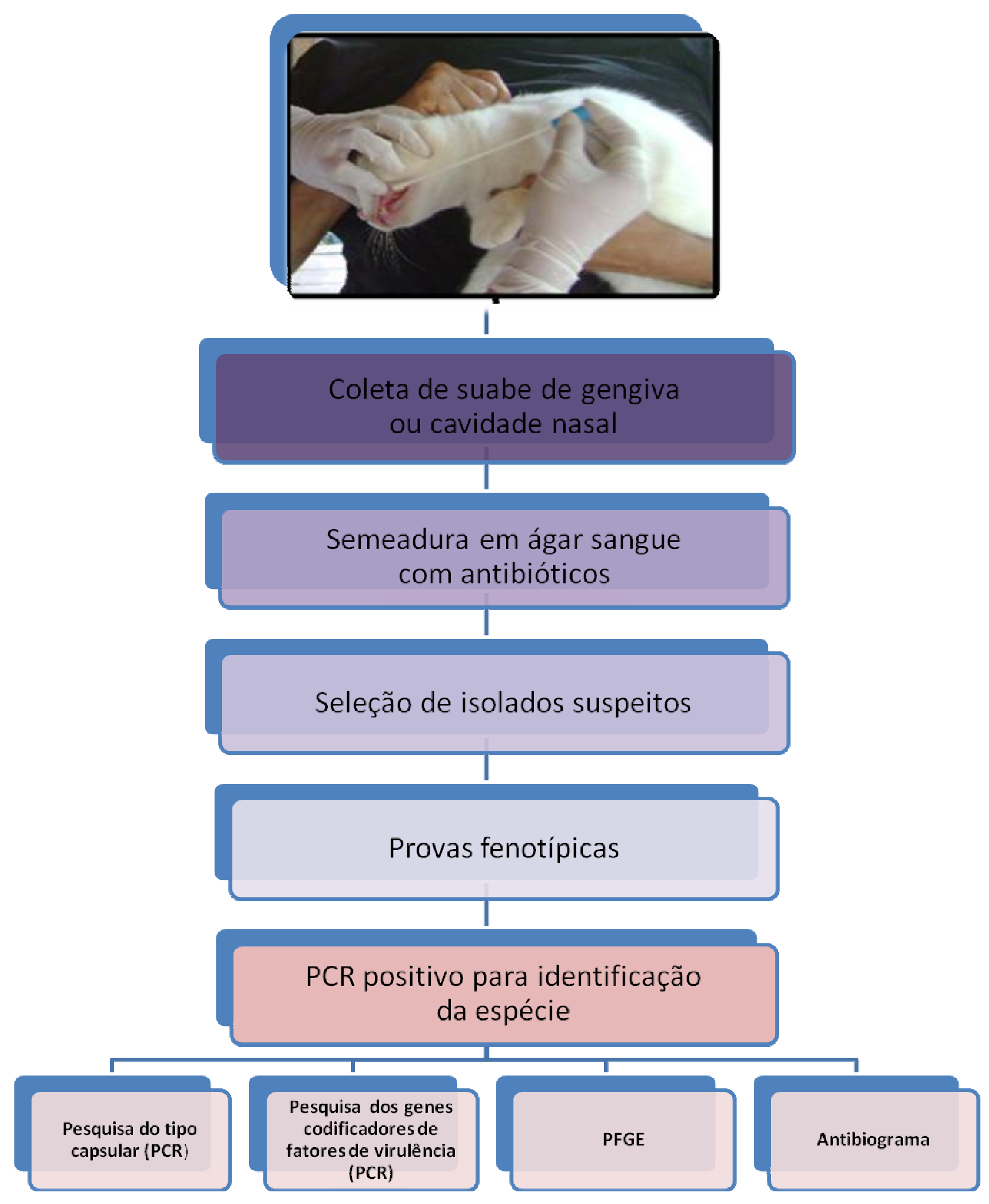

Figura 1- Diagrama esquemático descrevendo as atividades laboratoriais 


\subsection{PERFIL DE RESISTÊNCIA A ANTIMICROBIANOS}

Os perfis de sensibilidade antimicrobiana dos isolados foram analisados por meio da determinação do halo de inibição pela prova de disco-difusão (Kirby-Bauer) conforme padrões definidos no documento M31-A3 do CLSI (2008).

O inóculo bacteriano utilizado no teste de disco-difusão foi preparado à partir dos cultivos puros de P. multocida semeado em caldo infusão de cérebro-coração (BHI) por 24 horas a $37^{\circ} \mathrm{C}$. A turbidez do cultivo em caldo foi ajustada com solução salina estéril a 0,9\%, de modo a obter uma turbidez óptica comparável à da solução padrão 0,5 McFarland. Esta suspensão bacteriana ajustada contém aproximadamente 1 a $2 \times 10^{8} \mathrm{UFC} / \mathrm{mL}$.

Um suabe estéril foi introduzido no interior do tubo contendo a suspensão bacteriana ajustada, pressionado contra a parede do tubo a fim de remover 0 excesso da suspensão embebida na extremidade do suabe e então, estriado por toda a superfície do ágar Mueller Hinton com sangue de carneiro 5\%.

Após a semeadura do inóculo sobre a superfície do ágar, os discos impregnados com princípios antimicrobianos foram distribuídos individualmente. Foram utilizados os seguintes antimicrobianos: ceftiofur, penicilina, amoxacilina, florfenicol, norfloxacina, enrofloxacina, ciprofloxacina, tetraciclina, doxiciclina, sulfonamidas, cotrimoxazol, eritromicina.

As placas contendo inóculo e discos antimicrobianos foram incubadas em aerobiose a $37^{\circ} \mathrm{C}$ por 24 horas e então, examinadas quanto à formação de halos de inibição ao redor dos discos. 
Os diametros dos halos de inibiçãoformados no estudo foram interpretados conforme o quadro 1.

\begin{tabular}{|lccc|}
\hline \multicolumn{1}{|c}{ Agentes antimicrobianos } & \multicolumn{3}{c|}{ Halo de inibição $(\mathbf{m m})$} \\
\hline Amoxacilina & $\mathbf{S}^{\mathbf{a}}$ & $\mathbf{I}^{\mathbf{b}}$ & $\mathbf{R}^{\mathbf{c}}$ \\
Ceftiofur & $\geq 18$ & $14-17$ & $\leq 13$ \\
Cotrimoxazol $^{\mathrm{d}}$ & $\geq 21$ & $18-20$ & $\leq 17$ \\
Doxiciclina $^{\text {En }}$ & $\geq 16$ & $11-15$ & $\leq 10$ \\
Enrofloxacina & $\geq 16$ & $13-15$ & $\leq 12$ \\
Norfloxacina & $\geq 21$ & $17-20$ & $\leq 16$ \\
Ciprofloxacina & $\geq 21$ & $17-20$ & $\leq 16$ \\
Eritromicina & $\geq 21$ & $16-20$ & $\leq 15$ \\
Florfenicol & $\geq 23$ & $14-22$ & $\leq 13$ \\
Penicilina & $\geq 22$ & $19-21$ & $\leq 18$ \\
Sufonamidas & $\geq 28$ & $20-27$ & $\leq 19$ \\
Tetraciclina & $\geq 17$ & $13-16$ & $\leq 12$ \\
\hline
\end{tabular}

${ }^{A}$ sensível, ${ }^{b}$ intermediário, ${ }^{c}$ resistente $e^{d}$ associação de sulfametoxazol e trimetoprima.

${ }^{1} \mathrm{CLSI}$ - M31-A3 (2008)

${ }^{2}$ CLSI - M100-S15 (2005)

Quadro 1 - Critérios para interpretação dos halos de inibição do teste de discodifusão

\subsection{CARACTERIZAÇÃO GENOTÍPICA}

\subsubsection{Extração do DNA}

O genoma bacteriano foi purificado pela extração de DNA baseada nas propriedades de lise e inativação de nucleases do isotiocianato de guanidina junto às 
propriedades das partículas de terra diatomácea em ligar-se ao DNA ou RNA; este método foi descrito por Boom et al. (1990).

\subsubsection{Amplificação do DNA (PCR)}

A PCR foi realizada utilizando-se $5 \mu$ do DNA bacteriano, $1.5 \mathrm{mM}$ de $\mathrm{MgCl}_{2}$, 10 pmoles dos primers específicos para o agente e para os genes pesquisados (Quadro 2, 3 e 4 ), $1.0 \mathrm{U}$ de Taq DNA polimerase, 1X tampão de PCR e água até o volume final de $50 \mu \mathrm{l}$. 


\begin{tabular}{|c|c|c|c|c|}
\hline Alvo & Gene & Nome & Sequencia $\left(5^{\prime}-3^{\prime}\right)$ & Amplicon (pb) \\
\hline \multicolumn{5}{|l|}{ Espécie } \\
\hline P.multocida & KMT1 & $\begin{array}{l}\text { KMT1T7 } \\
\text { KMT1SP6 }\end{array}$ & $\begin{array}{l}\text { ATCCGCTATTTACCCAGTGG } \\
\text { GCTGTAAACGAACTCGCCAC }\end{array}$ & 460 \\
\hline \multicolumn{5}{|l|}{ Cápsula } \\
\hline$A$ & $\begin{array}{l}\text { hyaD- } \\
\text { hyaC }\end{array}$ & $\begin{array}{l}\text { CAPA- } \\
\text { FWD } \\
\text { CAPA- } \\
\text { REV }\end{array}$ & $\begin{array}{l}\text { TGCCAAAATCGCAGTCAG } \\
\text { TTGCCATCATTGTCAGTG }\end{array}$ & 1.044 \\
\hline B & $b c b D$ & $\begin{array}{l}\text { CAPB- } \\
\text { FWD } \\
\text { CAPB- } \\
\text { VER }\end{array}$ & $\begin{array}{l}\text { CATTTATCCAAGCTCCACC } \\
\text { GCCCGAGAGTTTCAATCC }\end{array}$ & 760 \\
\hline $\mathrm{D}$ & $d c b F$ & $\begin{array}{l}\text { CAPD- } \\
\text { FWD } \\
\text { CAPD- } \\
\text { VER }\end{array}$ & $\begin{array}{l}\text { TTACAAAAGAAAGACTAGGAGCCC } \\
\text { CATCTACCCACTCAACCATATCAG }\end{array}$ & 657 \\
\hline$E$ & ecbJ & $\begin{array}{l}\text { CAPE- } \\
\text { FWD } \\
\text { CAPE- } \\
\text { VER }\end{array}$ & $\begin{array}{l}\text { TCCGCAGAAAATTATTGACTC } \\
\text { GCTTGCTGCTTGATTTTGTC }\end{array}$ & 511 \\
\hline $\mathrm{F}$ & $f c b D$ & $\begin{array}{l}\text { CAPF- } \\
\text { FWD } \\
\text { CAPF- } \\
\text { REV }\end{array}$ & $\begin{array}{l}\text { AATCGGAGAACGCAGAAATCAG } \\
\text { TTCCGCCGTCAATTACTCTG }\end{array}$ & 851 \\
\hline
\end{tabular}

Fonte: Townsend et al. (1998)

Quadro 2 - Seqüência de primers utilizados para identificação de $P$. multocida e para tipagem capsular 


\begin{tabular}{|c|c|c|c|}
\hline Primer & Seqüência do primer (5'-3') & Gene & Referencia \\
\hline $\begin{array}{l}\text { Pm } 1 \text { A } \\
\text { Pm } 1 \text { B } \\
\text { Pm } 3 \text { A } \\
\text { Pm } 3 \text { B }\end{array}$ & $\begin{array}{l}\text { GGTCAGATGATGCTACATACTCC } \\
\text { CCAAACAGGGTTATATTCTGGAC } \\
\text { CAAGTCTTAACTCCTCCACAAGG } \\
\text { GGGCTTACTGAATCACAAGAGCC }\end{array}$ & $\operatorname{tox} A$ & Kamp et al, 1996 \\
\hline $\begin{array}{l}\text { P6 s } \\
\text { P6 as }\end{array}$ & $\begin{array}{l}\text { TCTGGATCCATGAAAAAACTAACTAAAGTA } \\
\text { AAGGATCCTTAGTATGTCAACACAGGACGACG }\end{array}$ & psl & Kasten et al. (1997) \\
\hline $\begin{array}{l}\text { OmpH s } \\
\text { OmpH as }\end{array}$ & $\begin{array}{l}\text { CGCGTATGAAGGTTAGGT } \\
\text { TTTAGATTGTGCGTAGTCAAC }\end{array}$ & $\mathrm{ompH}$ & Ewers et al, (2006) \\
\hline $\begin{array}{l}\text { Oma87s } \\
\text { Oma87-1 as }\end{array}$ & $\begin{array}{l}\text { ATGAAAAAACTTTTAATTGCGAGC } \\
\text { TGACTTGCGCAGTTGCATAAC }\end{array}$ & oma87 & Ewers et al, (2006) \\
\hline $\begin{array}{l}\text { Fim4 s } \\
\text { Fim4 as }\end{array}$ & $\begin{array}{l}\text { TGTGGAATTCAGCATTTTAGTGTGTC } \\
\text { TCATGAATTCTTATGCGCAAAATCCTGCTGG }\end{array}$ & $p t f A$ & Doughty et al. (2000) \\
\hline $\begin{array}{l}\text { TbPA s } \\
\text { TbPA as }\end{array}$ & $\begin{array}{l}\text { TTGGTTGGAAACCGTAAAAGC } \\
\text { TAACGTGTACGCAAAAGCCC }\end{array}$ & $t b P A$ & Ewers et al, (2006) \\
\hline $\begin{array}{l}\text { NanB1 s } \\
\text { NanB1 as }\end{array}$ & $\begin{array}{l}\text { GTCCTATAAAGTGACGCCGA } \\
\text { ACAGCAAAGGAAGACTGTCC }\end{array}$ & nanB & Ewers et al, (2006) \\
\hline $\begin{array}{l}\text { NanH1 s } \\
\text { NanH1 as }\end{array}$ & $\begin{array}{l}\text { GAATATTTGGGCGGCAACA } \\
\text { TTCTCGCCCTGTCATCACT } \\
\end{array}$ & nanH & Ewers et al, (2006) \\
\hline $\begin{array}{l}\text { ExbB s } \\
\text { TonB as }\end{array}$ & $\begin{array}{l}\text { GGTGGTGATATTGATGCGGC } \\
\text { GCATCATGCGTGCACGGTT }\end{array}$ & $\begin{array}{c}\text { exbBD } \\
\text { tonB }\end{array}$ & Ewers et al, (2006) \\
\hline $\begin{array}{l}\text { SodA s } \\
\text { SodA as }\end{array}$ & $\begin{array}{l}\text { TACCAGAATTAGGCTACGC } \\
\text { GAAACGGGTTGCTGCCGCT }\end{array}$ & sodA & Ewers et al, (2006) \\
\hline $\begin{array}{l}\text { SodC s } \\
\text { SodC as }\end{array}$ & $\begin{array}{l}\text { AGTTAGTAGCGGGGTTGGCA } \\
\text { TGGTGCGGGTGATCATCATG }\end{array}$ & sodC & $\begin{array}{l}\text { Lainson et al. (1996) } \\
\text { e Ewers et al, (2006) }\end{array}$ \\
\hline $\begin{array}{l}\text { Pfha1 s } \\
\text { Pfha1 as }\end{array}$ & $\begin{array}{l}\text { AGCTGATCAAGTGGTGAAC } \\
\text { TGGTACATTGGTGAATGCTG }\end{array}$ & pfhA & Ewers et al, (2006) \\
\hline $\begin{array}{l}\text { HgbA s } \\
\text { HgbA as }\end{array}$ & $\begin{array}{l}\text { TGGCGGATAGTCATCAAG } \\
\text { CCAAAGAACCACTACCCA }\end{array}$ & $h g h A$ & Ewers et al, (2006) \\
\hline $\begin{array}{l}\mathrm{HgbB} \text { s } \\
\mathrm{HgbB} \text { as }\end{array}$ & $\begin{array}{l}\text { ACCGCGTTGGAATTATGATTG } \\
\text { CATTGAGTACGGCTTGACAT }\end{array}$ & $h g b B$ & Ewers et al, (2006) \\
\hline $\begin{array}{l}\text { FimA s } \\
\text { FimA as }\end{array}$ & $\begin{array}{l}\text { CCATCGGATCTAAACGACCTA } \\
\text { AGTATTAGTTCCTGCGGGTG }\end{array}$ & $\operatorname{fim} A$ & Tang et al, (2009) \\
\hline $\begin{array}{l}\text { Hsf-1 s } \\
\text { Hsf-1 as }\end{array}$ & $\begin{array}{l}\text { TTGAGTCGGCTGTAGAGTTCG } \\
\text { ACTCTTTAGCAGTGGGGACAACCTC }\end{array}$ & Hsf1 & Tang et al, (2009) \\
\hline $\begin{array}{l}\text { Hsf-2 s } \\
\text { Hsf-2 as }\end{array}$ & $\begin{array}{l}\text { ACCGCAACCATGCTCTTAC } \\
\text { TGACTGACATCGGCGGTAC }\end{array}$ & Hsf2 & Tang et al, (2009) \\
\hline $\begin{array}{l}\text { TadD s } \\
\text { TadD as }\end{array}$ & $\begin{array}{l}\text { TCTACCCATTCTCAGCAAGGC } \\
\text { ATCATTTCGGGCATTCACC }\end{array}$ & $\operatorname{tad} D$ & Tang et al, (2009) \\
\hline $\begin{array}{l}\text { Fur s } \\
\text { Fur as }\end{array}$ & $\begin{array}{l}\text { GTTTACCGTGTATTAGACCA } \\
\text { CATTACTACATTTGCCATAC }\end{array}$ & fur & Tang et al, (2009) \\
\hline $\begin{array}{l}\text { PmHAS s } \\
\text { PmHAS as }\end{array}$ & $\begin{array}{l}\text { TCAATGTTTGCGATAGTCCGTTAG } \\
\text { TGGCGAATGATCGGTGATAGA }\end{array}$ & $p m H A$ & Tang et al, (2009) \\
\hline $\begin{array}{l}\text { OmpA s } \\
\text { OmpA as }\end{array}$ & $\begin{array}{l}\text { CGCATAGCACTCAAGTTTCTCC } \\
\text { CATAAACAGATTGACCGAAACG } \\
\end{array}$ & ompA & Tang et al, (2009) \\
\hline $\begin{array}{l}\text { PlpB s } \\
\text { PlpB as }\end{array}$ & $\begin{array}{l}\text { TTTGGTGGTGCGTATGTCTTCT } \\
\text { AGTCACTTTAGATTGTGCGTAG }\end{array}$ & $p / p B$ & Tang et al, (2009) \\
\hline
\end{tabular}

Quadro 3 - Seqüência dos primers para detecção dos genes codificadores de fatores de virulência de $P$. multocida 


\begin{tabular}{|l|l|l|}
\hline Reação & Genes & Fragmentos (pb) \\
\hline FV1 & hgbA, ptfA, hgbB, exbBD/tonB & $419,488,788,1144$ \\
FV3 & nanH, psl, nanB & $360,439,584$ \\
FV4 & ompH, oma87 & 438,949 \\
FV5 & sodA sodC & 275,235 \\
FV6 & tbPA & 361 \\
FV7 & fimA; pmHAS; Ompa & 728 \\
FV8 & hsf1; hsf2; fur & $866 ; 430 ; 201$ \\
FV9 & tadD; plpB & $654 ; 433 ; 244$ \\
\hline
\end{tabular}

Quadro 4- Reações utilizadas para detecção dos genes codificadores de fatores de virulência e tamanho dos fragmentos amplificados

\subsubsection{Detecção do produto de amplificação (amplicon)}

A detecção dos produtos de amplificação (10 1 l produto e $1 \mu$ l do corante Blue Green®) foi realizada através da eletroforese em gel de agarose 1,5\%, utilizando-se tampão TAE (0,04 M tris-acetato [pH 8,5], 0,002 M de EDTA). O gel foi fotografado através de luz ultravioleta em sistema de fotodocumentação convencional (Image Master, GE Healthcare). Os fragmentos foram identificados com base na utilização do marcador 100 bp DNA Ladder. 


\subsection{ELETROFORESE EM CAMPO PULSADO (PFGE)}

As amostras foram submetidas ao perfil de macrorestrição através de ensaios de PFGE utilizando o sistema de eletroforese CHEF DR III Chiller System (BioRad). Em resumo, uma alíquota do cultivo bacteriano padronizada na diluição $1 \times 10^{9}$, foi incorporada em agarose de baixo ponto de fusão e, após homogeneização, transferidas para moldes plásticos. Os plugs de agarose resultantes contendo a amostra foram então submetidos a um processo de lise in situ e, posteriormente, estocados em tampão Tris-EDTA até o momento da eletroforese. Uma fração do plug foi submetida à digestão com a enzima de restrição (Apal) e posteriormente adicionada ao gel de agarose 1\%. A eletroforese foi conduzida num período de $20 \mathrm{~h}$ a $6 \mathrm{~V} / \mathrm{cm}$, ângulo fixo de $120^{\circ}$, com pulso inicial de 2,0 s e final de 20 s, em tampão TBE $0,5 \mathrm{X}$ mantido a $14^{\circ} \mathrm{C}$. $\mathrm{O}$ gel foi corado por 20 minutos hora em corante Gel red® (Biotium) e a visualização dos fragmentos foi realizada sob iluminação ultravioleta em sistema de foto-documentação ImageMaster $^{\circledR}$ (GE Healthcare). Os fragmentos foram identificados com base na utilização de um marcador de alto peso molecular $\lambda$ DNA-PFG Marker (New England Biolabs). 


\subsection{DETERMINAÇÃO DO ÍNDICE DISCRIMINATÓRIO (ID)}

Os resultados obtidos através da caracterização genotípica foram analisados segundo o método numérico descrito por Hunter e Gaston (1988).

\subsection{ANÁLISE ESTATÍSTICA DOS FRAGMENTOS AMPLIFICADOS}

Para análise estatística dos fragmentos obtidos através da PFGE foi utilizado o programa BioNumerics 6.6 (Applied Maths). A similaridade das amostras foi estimada através do coeficiente de Dice. Com a matriz de similaridade gerada por este coeficiente foi possível determinar os grupos pelo método de UPGMA ("Unweighthed Pair-Group Method Using Arithmetic Average"), que está representado pela forma de dendrograma. As amostras que apresentaram quatro ou mais bandas diferentes foram classificadas em diferentes pulsotipos. 


\section{RESULTADOS}

Foram examinados 640 animais, sendo 191 gatos, 309 cães e 140 coelhos. A partir das culturas obtidas destes animais foram selecionadas 511 colônias com morfologia e características bioquímicas sugestivas para Pasteurella spp, destas, 93 foram confirmadas como P. multocida através das provas bioquímicas e da PCR.

Dentre os animais examinados $8,1 \%$ foram positivos para o isolamento de $P$. multocida, sendo que entre os gatos avaliados a freqüência de positivos foi $10,4 \%$, entre os cães foi de $0,9 \%$ e entre os coelhos de $20,7 \%$. O número de animais positivos nos diferentes meses de coleta e a origem das amostras são descritos nas tabelas 1 e 2 . 
Tabela 1- Resultados obtidos nas coletas realizadas em cães e gatos entre fevereiro de 2008 e dezembro de 2010

\begin{tabular}{|c|c|c|c|c|c|c|c|}
\hline \multirow{2}{*}{\multicolumn{2}{|c|}{ Ano/Mês }} & \multicolumn{3}{|c|}{ Cães } & \multicolumn{3}{|c|}{ Gatos } \\
\hline & & Testado & Positivo & Origem & Testado & Positivo & Origem \\
\hline \multirow{7}{*}{2008} & Fevereiro & 3 & 0 & Clínica & 7 & 0 & Clínica \\
\hline & Março & 10 & 0 & Clínica & 13 & 1 & Clínica \\
\hline & Maio & 4 & 0 & Clínica & 4 & 3 & Clínica \\
\hline & Julho & 9 & 0 & Clínica & 3 & 0 & Clínica \\
\hline & Agosto & 40 & 1 & Canil & 18 & 1 & Clínica \\
\hline & Novembro & 7 & 0 & Clínica & 0 & 0 & - \\
\hline & Dezembro & 6 & 0 & Clínica & 1 & 1 & Clínica \\
\hline \multirow{9}{*}{2009} & Fevereiro & 6 & 0 & Clínica & 4 & 1 & Clínica \\
\hline & Março & 31 & 0 & Clínica & 0 & 0 & Clínica \\
\hline & Maio & 16 & 0 & Clínica & 23 & 3 & Gatil \\
\hline & Junho & 31 & 0 & Clínica & 17 & 3 & Clínica \\
\hline & Agosto & 9 & 1 & Canil & 7 & 3 & Clínica \\
\hline & Setembro & 0 & 0 & - & 9 & 0 & Clínica \\
\hline & Outubro & 2 & 0 & Clínica & 37 & 0 & Clínica/ Gatil \\
\hline & Novembro & 5 & 0 & Clínica & 3 & 0 & Clínica \\
\hline & Dezembro & 3 & 0 & Clínica & 1 & 0 & Clínica \\
\hline \multirow{9}{*}{2010} & Fevereiro & 0 & 0 & ONG & 29 & 0 & ONG \\
\hline & Março & 53 & 0 & ONG & 3 & 0 & Clínica \\
\hline & Abril & 10 & 0 & Clínica & 2 & 0 & Clínica \\
\hline & Maio & 6 & 0 & Clínica & 0 & 0 & - \\
\hline & junho & 16 & 0 & Clínica & 0 & 0 & - \\
\hline & Julho & 13 & 1 & Clínica & 3 & 0 & Clínica \\
\hline & Agosto & 4 & 0 & Clínica & 5 & 2 & Clínica \\
\hline & Setembro & 2 & 0 & Clínica & 0 & 0 & - \\
\hline & Outubro & 3 & 0 & Clínica & 0 & 0 & - \\
\hline 2011 & Fevereiro & 20 & 0 & Canil & 2 & 2 & Clínica \\
\hline \multicolumn{2}{|c|}{ Total } & 289 & 3 & & 191 & 20 & \\
\hline
\end{tabular}

Tabela 2- Resultados obtidos nas coletas realizadas em coelhos entre Setembro de 2010 e Abril de 2011.

\begin{tabular}{llccl}
\hline Ano & Mês & Testados & Positivos & Origem \\
\hline \multirow{2}{*}{2010} & Setembro & 20 & 2 & Coelhario B \\
& Outubro & 40 & 21 & Coelhario A \\
\cline { 2 - 5 } 2011 & Fevereiro & 27 & 2 & Coelhario D \\
& Abril & 53 & 4 & Coelhario C \\
\hline \multirow{2}{*}{ Total } & & 140 & 29 & \\
\hline
\end{tabular}




\section{Determinação do tipo capsular}

O tipo capsular foi determinado através da PCR onde das 93 colônias selecionadas 57 eram cápsula tipo A e 36 não foram positivas para nenhum tipo de cápsula.

Detecção do gene codificador da toxina dermonecrótica

Nenhuma das colônias selecionadas apresentou o gene codificador da toxina dermonecrótica.

Detecção dos genes codificadores de proteínas e fatores de virulência

Foram detectadas diferentes frequências dos genes codificadores de diferentes proteínas e fatores de virulência nas 93 cepas testadas. Dado apresentado na tabela 3 . Os perfis gerados pela pesquisa dos genes codificadores dos fatores de virulência são apresentados na figura 3. 
Tabela 3- Frequência de genes codificadores de proteínas e fatores de virulência nas amostras de $P$. multocida provenientes de cães, gatos e coelhos

\begin{tabular}{clc}
\hline Gene & \multicolumn{1}{c}{ Fator } & N. positivos (\%) \\
\hline toxA & Toxina dermonecrótica & $0-(0)$ \\
$p s /$ & Porina & $89-(94,6)$ \\
ompH & Proteína externa de membrana H & $80-(86)$ \\
oma87 & Proteína externa de membrana 87 & $86-(92,4)$ \\
ptfA & Subunidade de fimbria tipo 4 & $72-(77,4)$ \\
tbpA & $\quad$ Proteína ligadora de transferrina & $4-(4,3)$ \\
nanB & Proteína associada à membrana externa & $90-(96,7)$ \\
nanH & Proteína associada à membrana externa & $71-(76,3)$ \\
exbBD e tonB & Proteína transportadora de ferro & $72-(77,4)$ \\
sodA & Superoxido desmutase & $77-(82,7)$ \\
sodC & Superoxido desmutase & $72-(77,4)$ \\
pfhA & Hemaglutinina filamentosa & $1-(1)$ \\
$h g b A$ & Proteina ligadora de hemoglobina & $59-(63,4)$ \\
$h g b B$ & Proteina ligadora de hemoglobina & $52-(55,9)$ \\
fimA & Fimbria & $57-(61,2)$ \\
$h s f 1$ & Adesina de autotransporte & $21-(22,5)$ \\
$h s f 2$ & Adesina de autotransporte & $45-(48,3)$ \\
tadD & Proteína D de aderência não específica & $52-(55,9)$ \\
fur & Proteína reguladora da captação de ferro & $9-(9,6)$ \\
pmHAS & Sintase de Hialuronidase & $64-(68,8)$ \\
ompA & Proteína externa de membrana A & $27-(29)$ \\
plpB & Lipoproteína B & $37-(39,7)$ \\
\hline
\end{tabular}




\section{Eletroforese em Campo Pulsado (PFGE)}

Todas as 93 cepas selecionadas de $P$ multocida foram analisadas através da PFGE utilizando a enzima Apal. O numero de fragmentos de DNA gerados por perfil variou entre 7 e 18. Foram observados 39 pulsotipos a partir das 93 cepas testadas, O índice discriminatório obtido pela PFGE foi de 0,97.

A partir dos dendrogramas (Figuras 2 e 3 ) podem ser observados dois grupos principais I e II, com coeficiente de similaridade inferior a $40 \%$. O grupo I constituiuse por 16 amostras de cães e gatos em sua maioria exceto por uma amostra de coelho, distribuídas em 6 pulsotipos ( $\mathrm{P} 34,35,36,37,38$ e 39), dentre estes 0 pulsotipo 36 se destaca por ser o mais homogêneo em relação a distribuição dos fatores de virulência (todas as amostras foram positivas para os genes $h g B b$, exbBD, nanH, psl, nanB, ompH,oma87, sodC, sodA e pmHAS) e em relação ao perfil de resistência antimicrobiana onde apenas uma amostra de cão foi sensível a todas as drogas testadas e as outras amostras foram resistentes ao cotrimoxazol. Os animais destes subgrupos pertenciam a proprietários particulares.

O grupo II reuniu 77 amostras, distribuídas em 33 pulsotipos com coeficiente de similaridade entre as mesmas variando entre $40 \%$ a $100 \%$. Dentro do grupo II, o subgrupo Ila agrupou 17 amostras de gatos, onde os pulsotipos 28,31 e 32 agruparam 7 amostras clonais pertencentes a 3 animais diferentes, dentre estes clones as amostras pertencentes ao pulsotipo 32 (94.1 e 94.3) destacam-se por serem resistentes a diferentes drogas antimicrobianas (norfloxacina, enrofloxacina, ciprofloxacina, sulfonamidas e cotrimoxazol), nenhuma das amostras clonais apresentou a mesma distribuição de genes para os fatores de virulência. 
O subgrupo Ilb, por sua vez, foi fragmentado em outros subgrupos, constituídos por diferentes pulsotipos, dentre os quais, destaca-se o subgrupo formado pelos pulsotipos 1 a 11 (Tabela 4) por agrupar 36 amostras de coelhos em com um coeficiente de similaridade variando entre 60 e 100\%. Neste subgrupo as amostras alocaram-se de acordo com sua origem e com o perfil de resistência. Por exemplo as amostras pertencentes ao coelhário A foram sensíveis a todas as drogas utilizadas e as amostras pertencentes ao coelhário C.resistentes a sulfonamidas. O pulsotipo 4 foi o único que reuniu duas amostras com distribuição idêntica dos fatores de virulência, as demais amostras tiveram uma distribuição quase constante dos genes psl, nanB, pfta, sodC e tadD.

Os outros subgrupos reuniram 24 amostras de cães, gatos e coelhos distribuídas em 16 pulsotipos diferentes (P 12 a 27), com coeficiente de similaridade variando entre 42 e 100\%. As amostras de gatos pertencentes aos pulsotipos 12 e 15 apresentaram resistência às mesmas drogas (ceftiofur, sulfonamidas e cotrimoxazol) tendo como origem ONGS da cidade de São Paulo. Já as amostras de cães agrupadas nos pulsotipos 14 e 26 foram todas sensíveis às drogas testadas no estudo. Todas as amostras agrupadas nestes pulsotipos (P12 a 27) tiveram em comum a presença do gene oma87. O gene pfha esteve presente em uma única amostra de cão (P14) dentre todas as amostras testadas no estudo. 


\section{Perfil de sensibilidade antimicrobiana}

Dentre as cepas selecionadas $22,5 \%$ (21) cepas foram sensíveis a todas as drogas testadas (ceftiofur, penicilina, amoxacilina, florfenicol, norfloxacina, enrofloxacina, ciprofloxacina, tetraciclina, doxiciclina, eritromicina, sulfonamidas, cotrimoxazol). $77,4 \%$ (72) das cepas foram resistentes a pelo menos uma droga utilizada e 5,3\% (5) foram multiresistentes (cepas que apresentavam resistência a três ou mais drogas). A resistência bacteriana foi bastante evidente frente à sulfonamidas e o cotrimoxazol (32 cepas), apenas sete cepas foram resistentes apenas ao cotrimoxazol e 12 resistentes apenas a sulfonamidas, cinco foram resistentes a eritromicina e sete a penicilinas, algumas cepas também foram resistentes á amoxacilina, ceftiofur, enrofloxacina e norfloxacina. Os perfis de resistência podem ser claramente observados na figura 2. 
Tabela 4- Caracterização dos pulsotipos gerados através da PFGE em cepas de $P$. multocida

\begin{tabular}{|c|c|c|c|c|c|}
\hline Pulsotipo & Ident. & Espécie $^{1}$ & Origem $^{2}$ & Animal & Capsula \\
\hline $\mathrm{P} 1$ & $45.1 \mathrm{c}, 98.3 \mathrm{C}$ & Rabbit & Herd A, Herd C & $45 \mathrm{C}, 98 \mathrm{C}$ & Cap $\mathrm{A}, \mathrm{NT}^{3}$ \\
\hline P2 & $\begin{array}{c}24.2 \mathrm{c}, 37.3 \mathrm{c}, 92.4 \mathrm{bc}, 95.1 \mathrm{c} \\
95.2 \mathrm{c}, 98.1 \mathrm{C}, 98.2 \mathrm{C}\end{array}$ & Rabbit & Herd A, Herd C & $\begin{array}{c}24 \mathrm{C}, 37 \mathrm{C}, 92 \mathrm{C}, 95 \mathrm{C} \\
98 \mathrm{C}\end{array}$ & Cap A \\
\hline P3 & $95.3 \mathrm{c}$ & Rabbit & Herd C & $95 \mathrm{C}$ & NT \\
\hline $\mathrm{P} 4$ & $51.3 \mathrm{c}, 51.4 \mathrm{c}, 52.3 \mathrm{bc}$ & Rabbit & Herd A & $51 \mathrm{C}, 52 \mathrm{C}$ & NT \\
\hline P5 & $146.2 c, 146.4 c, 59.3 c, 92.1 \mathrm{C}$ & Rabbit & $\begin{array}{c}\text { Herd D, Herd A } \\
\text { Herd C }\end{array}$ & $146 \mathrm{C}, 59 \mathrm{C}, 92 \mathrm{C}$ & NT \\
\hline P6 & $\begin{array}{c}23.2 \mathrm{c}, 29.1 \mathrm{c}, 40.3 \mathrm{c}, 48.1 \mathrm{c} \\
58.1 \mathrm{c}\end{array}$ & Rabbit & Herd A & $\begin{array}{c}23 \mathrm{C}, 29 \mathrm{C}, 40 \mathrm{C}, 48 \mathrm{C}, \\
58 \mathrm{C}\end{array}$ & Cap A \\
\hline $\mathrm{P} 7$ & $46.1 \mathrm{C}, 51.1 \mathrm{C}$ & Rabbit & Herd A & $46 \mathrm{C}, 51 \mathrm{C}$ & Cap A \\
\hline P8 & $90.2 \mathrm{C}$ & Rabbit & Herd C & $90 \mathrm{C}$ & NT \\
\hline P9 & $92.4 \mathrm{c}$ & Rabbit & Herd C & $92 \mathrm{C}$ & NT \\
\hline P10 & $39.2 C, 59.1 \mathrm{C}$ & Rabbit & Herd A & $39 \mathrm{C}, 59 \mathrm{C}$ & NT \\
\hline P11 & $\begin{array}{l}30.1 \mathrm{C}, 35.1 \mathrm{C}, 38.1 \mathrm{C}, 50.1 \mathrm{C}, \\
54.1 \mathrm{C}, 55.1 \mathrm{C}, 56.3 \mathrm{C}, 58.2 \mathrm{C}\end{array}$ & Rabbit & Herd A & $\begin{array}{l}30 \mathrm{C}, 35 \mathrm{C}, 38 \mathrm{C}, 50 \mathrm{C}, \\
54 \mathrm{C}, 55 \mathrm{C}, 56 \mathrm{C}, 58 \mathrm{C}\end{array}$ & Cap A \\
\hline $\mathrm{P} 12$ & 176.2 & Cat & Shelter & 176 & Cap A \\
\hline $\mathrm{P} 13$ & $467.3,467.4$ & Cat & Owner & 467 & NT \\
\hline P14 & 466.2 & Dog & Owner & 466 & Cap A \\
\hline P15 & 210.4 & Cat & Shelter & 210 & NT \\
\hline P16 & $146.6 \mathrm{c}, 52.4 \mathrm{c}$ & Rabbit & Herd D, Herd A & 146C, 52C & NT \\
\hline P17 & $49.1 \mathrm{C}, 52.1 \mathrm{C}$ & Rabbit & Herd A & $49 \mathrm{C}, 52 \mathrm{C}$ & Cap A \\
\hline P18 & 191.0 & Cat & Owner & 191 & Cap A \\
\hline P19 & 210.1 & Cat & Shelter & 210 & NT \\
\hline P20 & $73.3 \mathrm{C}$ & Rabbit & Herd B & $73 C$ & NT \\
\hline $\mathrm{P} 21$ & $471.1,471.2$ & Cat & Owner & 471 & NT, Cap A \\
\hline P22 & 73.2C, $77.1 \mathrm{C}, 77.3 \mathrm{C}$ & Rabbit & Herd B & $73 C, 77 C$ & NT \\
\hline P23 & $77.2 \mathrm{C}$ & Rabbit & Herd B & $77 \mathrm{C}$ & NT \\
\hline P24 & $470.2,470.3$ & Cat & Owner & 470 & Cap A, NT \\
\hline P25 & 470.1 & Cat & Owner & 470 & Cap A \\
\hline P26 & $459.2,459.3$ & Dog & Owner & 459 & Cap A, NT \\
\hline P27 & 185.1 & Cat & Shelter & 185 & NT \\
\hline P28 & $262.2,262.3,262.4$ & Cat & Owner & 262 & Cap A \\
\hline P29 & 66.1 & Cat & Owner & 66 & NT \\
\hline P30 & $214.2,221.4$ & Cat & Shelter & 214,221 & Cap A \\
\hline P31 & $260.1,93.1,93.2,93.3,93.4$ & Cat & Owner & 260,93 & Cap A \\
\hline P32 & $89.4,94.1,94.3$ & Cat & Owner & 89,94 & Cap A \\
\hline P33 & $210.2,260.2,260.4$ & Cat & Shelter, Owner & 210,260 & Cap A, NT \\
\hline P34 & $221.3,222.3$ & Cat & Shelter & 221,222 & Cap A, NT \\
\hline P35 & 466.4 & Cat & Owner & 466 & Cap A \\
\hline P36 & $\begin{array}{c}110.1,110.3,110.4,94.4 \\
95.1,95.2,95.4\end{array}$ & Dog, Cat & Shelter, Owner & $110,94,95$ & Cap A \\
\hline P37 & $256.1,256.2,256.3,256.4$ & Cat & Owner & 256 & Cap A \\
\hline P38 & $153.1 \mathrm{c}$ & Rabbit & Herd D & $153 \mathrm{C}$ & Cap A \\
\hline P39 & 223.2 & Cat & Shelter & 223 & Cap A \\
\hline
\end{tabular}

${ }^{1}$ Rabbit = coelho, Dog = cão, Cat= gato ${ }^{2}$ Herd= criatório, Owner= proprietário, Shelther= abrigo, ONG;

${ }^{3} \mathrm{NT}$ - negativa para todos os tipos capsulares. 

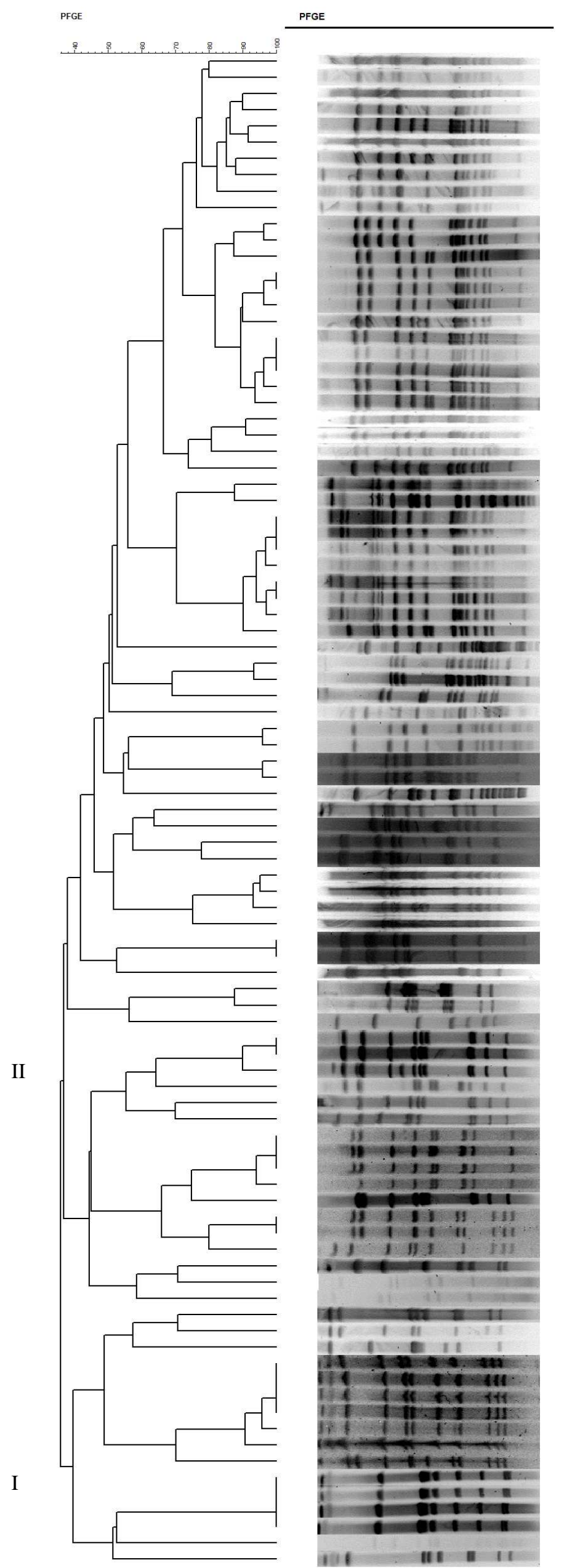

\begin{tabular}{|c|c|c|c|}
\hline Rabbit & Herd C & Animal $98 \mathrm{C}$ & SULSUT \\
\hline Rabbit & Herd A & Animal $45 \mathrm{C}$ & Sensible \\
\hline Rabbit & Herd C & Animal $98 \mathrm{C}$ & SUL \\
\hline Rabbit & Herd C & Animal 95C & SULSUT \\
\hline Rabbit & Herd A & Animal $37 \mathrm{C}$ & SULISUT \\
\hline Rabbit & Herd C & Animal $98 \mathrm{C}$ & SUL \\
\hline Rabbit & Herd C & Animal 92C & SULSUT \\
\hline Rabbit & Herd C & Animal $95 \mathrm{C}$ & SUL \\
\hline Rabbit & Herd A & Animal 24C & ERY \\
\hline Rabbit & Herd C & Animal $95 \mathrm{C}$ & SUL \\
\hline Rabbit & Herd A & Animal 51C & Sensible \\
\hline Rabbit & Herd A & Animal 51C & PEN/CFT \\
\hline Rabbit & Herd A & Animal 52C & AMO/PEN/CFT \\
\hline Rabbit & Herd D & Animal $146 \mathrm{C}$ & Sensible \\
\hline Rabbit & Herd D & Animal $146 \mathrm{C}$ & Sensible \\
\hline Rabbit & Herd A & Animal 59C & SULSUT \\
\hline Rabbit & Herd C & Animal 92C & PEN/CFT \\
\hline Rabbit & Herd A & Animal $23 \mathrm{C}$ & SUL \\
\hline Rabbit & Herd A & Animal 29C & Sensible \\
\hline Rabbit & Herd A & Animal $40 \mathrm{C}$ & SULSUT \\
\hline Rabbit & Herd A & Animal $58 \mathrm{C}$ & PEN/CFT \\
\hline Rabbit & Herd A & Animal $48 \mathrm{C}$ & PENCFT \\
\hline Rabbit & Herd A & Animal $46 \mathrm{C}$ & Sensible \\
\hline Rabbit & Herd A & Animal 51C & ERY \\
\hline Rabbit & Herd C & Animal 90C & SUL \\
\hline Rabbit & Herd C & Animal 92C & SULSUT \\
\hline Rabbit & Herd A & Animal 59C & Sensible \\
\hline Rabbit & Herd A & Animal $39 \mathrm{C}$ & SULSUT \\
\hline Rabbit & Herd A & Animal 54C & SUL \\
\hline Rabbit & Herd A & Animal $55 \mathrm{C}$ & Sensible \\
\hline Rabbit & Herd A & Animal 50C & SUL \\
\hline Rabbit & Herd A & Animal $58 \mathrm{C}$ & Sensible \\
\hline Rabbit & Herd A & Animal $56 \mathrm{C}$ & Sensible \\
\hline Rabbit & Herd A & Animal $38 \mathrm{C}$ & Sensible \\
\hline Rabbit & Herd A & Animal $35 \mathrm{C}$ & ERYISUL \\
\hline Rabbit & Herd A & Animal $30 \mathrm{C}$ & Sensible \\
\hline 176.2 & Shelter & Animal 176 & CFT/SULISUT \\
\hline 467.3 & Owner & Animal 467 & Sensible \\
\hline 467.4 & Owner & Animal 467 & Sensible \\
\hline 466.2 & Owner & Animal 466 & Sensible \\
\hline 210.4 & Shelter & Animal 210 & CFT/SULISUT \\
\hline Rabbit & Herd A & Animal 52C & SULSUT \\
\hline Rabbit & Herd D & Animal $146 \mathrm{C}$ & Sensible \\
\hline Rabbit & Herd A & Animal $49 \mathrm{C}$ & Sensible \\
\hline Rabbit & Herd A & Animal 52C & Sensible \\
\hline 191.0 & Owner & Animal 191 & PEN/CFT \\
\hline 210.1 & Shelter & Animal 210 & Sensible \\
\hline Rabbit & Herd B & Animal $73 \mathrm{C}$ & SUT \\
\hline 471.1 & Owner & Animal 471 & SULSUT \\
\hline 471.2 & Owner & Animal 471 & SULSUT \\
\hline Rabbit & Herd B & Animal $73 \mathrm{C}$ & SULISUT \\
\hline Rabbit & Herd B & Animal $77 \mathrm{C}$ & SULSUT \\
\hline Rabbit & Herd B & Animal $77 \mathrm{C}$ & SULSUT \\
\hline Rabbit & Herd B & Animal $77 \mathrm{C}$ & SULSUT \\
\hline 470.2 & Owner & Animal 470 & SUT \\
\hline 470.3 & Owner & Animal 470 & SULSUT \\
\hline 470.1 & Owner & Animal 470 & SULISUT \\
\hline 459.2 & Owner & Animal 459 & Sensible \\
\hline Dog & Owner & Animal 459 & Sensible \\
\hline 185.1 & Shelter & Animal 185 & ERY \\
\hline 262.2 & Owner & Animal 262 & SUL \\
\hline 262.3 & Owner & Animal 262 & SULUSUT \\
\hline 262.4 & Owner & Animal 262 & ERYISULISUT \\
\hline Cat & Owner & Animal 66 & SUL \\
\hline 214.2 & Shelter & Animal 214 & SULSUT \\
\hline 221.4 & Shelter & Animal 221 & Sensible \\
\hline Cat & Owner & Animal 93 & sul \\
\hline Cat & Owner & Animal 93 & SULSUT \\
\hline Cat & Owner & Animal 93 & SULSUT \\
\hline Cat & Owner & Animal 93 & SULISUT \\
\hline 260.1 & Owner & Animal 260 & SULSUT \\
\hline Cat & Owner & Animal 94 & NOR/ENO/CIP/SULSUT \\
\hline Cat & Owner & Animal 94 & SULSUT \\
\hline Cat & Owner & Animal 89 & SUT \\
\hline Cat & Shelter & Animal 210 & SULSUT \\
\hline 260.4 & Owner & Animal 260 & PEN/CFT \\
\hline 260.2 & Owner & Animal 260 & PEN/CFT \\
\hline 222.3 & Shelter & Animal 222 & Sensible \\
\hline 221.3 & Shelter & Animal 221 & SUT \\
\hline 466.4 & Owner & Animal 466 & SULSUT \\
\hline Cat & Owner & Animal 95 & SUT \\
\hline Dog & Owner & Animal 110 & SULSUT \\
\hline 110.3 & Owner & Animal 110 & SULSUT \\
\hline 110.4 & Owner & Animal 110 & Sensible \\
\hline Cat & Owner & Animal 95 & SULSUT \\
\hline Cat & Owner & Animal 95 & SUT \\
\hline Cat & Shelter & Animal 94 & SUT \\
\hline 256.1 & Owner & Animal 256 & SULSUT \\
\hline 256.2 & Owner & Animal 256 & SULSUT \\
\hline Cat & Owner & Animal 256 & SULSUT \\
\hline Cat & Owner & Animal 256 & SULSUT \\
\hline Rabbit & Herd D & Animal $153 \mathrm{C}$ & Sensible \\
\hline Cat & Shelter & Animal 223 & SUL \\
\hline
\end{tabular}

Figura 2 - Dendrograma criado para análise dos resultados da PFGE baseado no coeficiente de Dice e UPGMA. Cepas de $P$. multocida isoladas de cães, gatos e coelhos 


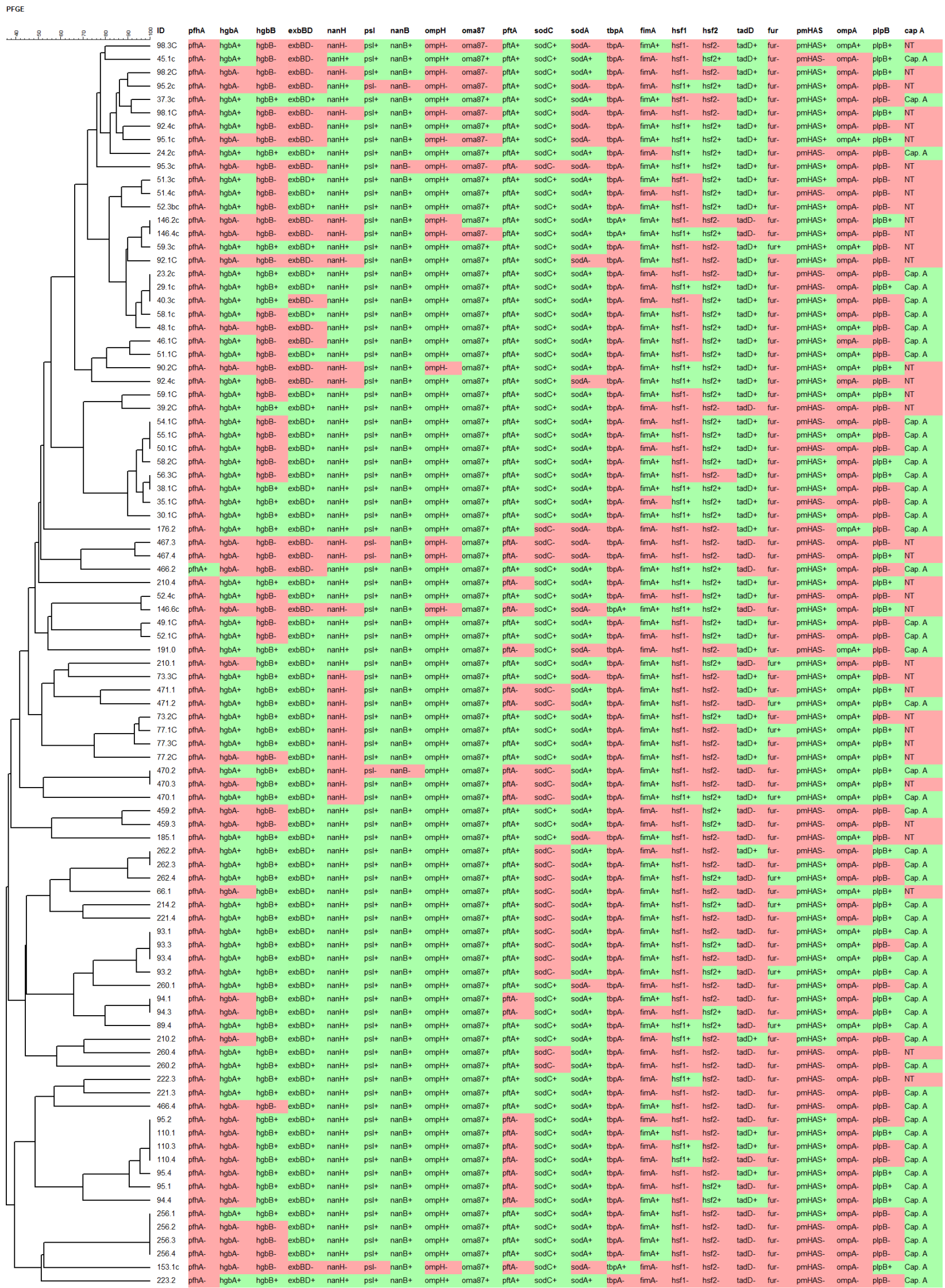

Figura 3 - Dendrograma criado para análise dos resultados da PFGE baseado no coeficiente de Dice e UPGMA. Cepas de $P$. multocida isoladas de cães, gatos e coelhos. Presença dos genes codificadores de fatores de virulência e tipo capsular. (verde - amostras positivas e vermelho - amostras negativas) 


\section{DISCUSSÃO}

As bactérias da espécie Pasteurella multocida têm sido descritas como um grupo geneticamente heterogêneo, dividido em subespécies diferentes como multocida, gallicida, séptica e tigris, e que acometem diferentes hospedeiros, causando variadas doenças com relevantes perdas econômicas.

No presente estudo foram avaliadas 93 cepas isoladas de cães, gatos e coelhos, provenientes do Estado de São Paulo. Dentre os resultados obtidos a freqüência de isolamento do agente foi inferior ao relatado por alguns autores como Grieco et al .(1995) que relatam frequências de 70 a $90 \%$ dos gatos examinados e 50 a $66 \%$ dos cães portadores de $P$. multocida na microbiota oral. Esta frequência bastante inferior $(10,4 \%$ dos gatos e $0,9 \%$ dos cães) pode estar relacionada aos métodos de isolamento empregados, a interferência da microbiota oral que dificulta o isolamento do agente, ou a diferenças geográficas.

Uma freqüência que varia de sete a quase $100 \%$ de $P$. multocida no trato respiratório superior de coelhos de diferentes origens foi relatada por Anina et al. (2009), sendo a frequência encontrada no presente estudo igual a 20,7 \%. Relatos de infecção humana a partir do contato com coelhos são bem menos freqüentes que os relatos de contaminação a partir de gatos. Silberfein et al. (2006) descrevem um caso de infecção humana pelo agente após mordida de coelho, este dado associado a alta ocorrência do agente nesta espécie em nosso meio reforça o potencial zoonótico da $P$. multocida. 
A PFGE tem sido uma importante ferramenta utilizada para se estabelecer uma relação epidemiológica entre os isolados clínicos de $P$. multocida de humanos que estiveram em contato com animais de estimação ou não e os isolados destes animais em questão (LIU et al., 2003).

A aplicação da PFGE na discriminação de amostras de $P$. multocida sido relatada em vários estudos (TOWSEND et al., 1997). Marois et al. (2009) em estudo realizado com amostras de $P$. multocida isoladas da orofaringe de suínos e de humanos infectados observaram significantes associações entre os isolados, como uma baixa variabilidade entre estes e a ocorrência de padrões coincidentes entre suínos e humanos sugerindo a possibilidade de transmissão do agente entre as duas espécies (MAROIS et al., 2009).

No presente estudo foi possível observar uma forte tendência de agrupamento das amostras isoladas de coelhos, quando comparadas as de cães e gatos. A maioria das amostras pertencentes ao mesmo animal foram agrupadas no mesmo pulsotipo, no entanto foram observados também animais portando cepas com perfis distintos através da PFGE. Não houve correlação dos grupos formados através das PFGE com os dados obtidos através da avaliação dos perfis de resistência e dos genes codificadores de fatores de virulência. 
A partir dos cães, gatos e coelhos positivos foram selecionados 93 isolados. Estes isolados foram submetidos a PCR para toxina dermonecrótica, sendo todos negativos. Este resultado pode estar relacionado ao fato do gene codificador da toxina dermonecrótica ser mais relacionado aos quadros de rinite na espécie suína, sendo descrito em menor frequência também em ovinos e aves (EWERS et al., 2006). Mesmo na espécie suína a prevalência de isolados toxigênicos é baixa e ou se reduz após alguns repiques, pois o gene codificador da toxina não está inserido no cromossomo bacteriano e sim de um bacteriófago lisogênico que infecta o agente (PULLINGER et al., 2004).

Através da PCR, $61,2 \%$ das cepas foram positivas para o tipo capsular A, dado também encontrado em outros estudos que relatam a maior ocorrência deste tipo capsular nas três espécies animais avaliadas (ARUMUGAM et al., 2011). Uma característica não esperada das cepas do presente estudo foi a alta frequência de cepas não tipáveis para o gene codificador da cápsula (38,7\%) através da PCR. Este número é ligeiramente superior ao estudo mais recente, realizado por Arumugam et al. (2011) usando a mesma reação de PCR descrita por Townsend et al. (1998), onde a frequência de amostras não tipáveis descrita foi de 19,3\% (22/114). Outros estudos descrevendo frequências inferiores de cepas não tipáveis através da PCR relatam frequências de 2 a 9\% (DAVIES et al., 2003a; b; JAMALUDIN et al., 2005; EWERS et al., 2006; TANG et al., 2009).

Utilizando a sorotipagem através de métodos fenotípicos convencionais, Arumugam et al. (2011) descrevem uma porcentagem ainda maior de cepas não tipáveis, subindo de $19,3 \%$ para $48,2 \%$ (55/114) das cepas de P. multocida avaliadas. 
A expressão de um tipo capsular é um fator critico para o grau de virulência de uma amostra, sabe-se que fatores ambientais como o crescimento na presença de antibióticos, perda de ferro ou de fontes de ferro como a hemoglobina afetam a sua expressão (STEEN et al., 2010). Muitos estudos têm relatado a perda espontânea de cápsulas em isolados de $P$. multocida que sofreram muitas passagens in vitro, mas o mecanismo através do qual estas perdas ocorrem ainda não totalmente foi determinado. Steen et al. (2010) sugerem que uma redução na transcrição dos genes dentro do lócus de biossíntese da cápsula, pode ser uma das causas para a perda espontânea de cápsula que ocorre em algumas cepas. (CHAMPLIN et al., 1999; STEEN et al., 2010). No entanto, apesar de haver várias descrições prévias, nenhum dos estudos atuais explica a ausência dos loci relacionados aos tipos capsulares conhecidos até o momento ( $A, B, D, E$ e F) através da PCR.

Entre os 93 isolados a prevalência dos genes codificadores de proteínas e fatores de virulência variou de $1 \%$ como no caso da hemaglutinina filamentosa (pfhA) a 96,7\% como no caso das proteínas associadas a membrana externa celular (nanB).

No presente estudo o gene codificador da hemaglutinina filamentosa $(p f h A)$ foi detectado em apenas uma amostra originada de um cão. Ewers et al. (2006) descrevem uma freqüência superior em diferentes espécies, $25 \%$ em isolados de cães, $18,5 \%$ em gatos e $21,2 \%$ em suínos. Em isolados de origem suína Tang et al (2009) descrevem $15 \%$ de isolados positivos e Astrid et a.I (2009) descrevem 20\%.

Segundo Sina et al.(2006) e Ewers et al. (2006), o gene tbpA esta intimamente relacionado cepas de ruminantes (bovinos, ovinos e bubalinos), o que justifica sua baixa freqüência $(4,3 \%)$ nas cepas do presente estudo. 
Os outros genes codificadores de proteínas com diferentes funções como a aquisição de ferro (exbBd e tonB - 77,4\%), proteínas ligadoras de hemoglobina ( $h g b A-63,4 \%$ e $h g b B-55,9 \%$ ), superóxido desmutase (sodA - 82,7\% e sodC $77,4 \%$ ), subunidade de fimbria tipo 4 (ptfA - 77,4\%), porina (ps/94,6\%) e outras proteínas de membrana (omph - 86\% e nanH - 76,3\%) tiveram freqüências semelhantes as relatadas por Ewers et al. (2006).

Em contraste com outros estudos como o de Tang et al. (2009), no presente estudo não foi possível associar um determinado fator de virulência a um tipo capsular especifico, já que distribuição dos fatores de virulência foi muito heterogênea entre os isolados com tipo capsular A e os isolados não tipaveis.

Infecções causadas por $P$. multocida normalmente são tratadas por um amplo espectro de antibióticos (KEHRENBERG et al., 2001). Os dados de susceptibilidade antimicrobiana do presente estudo indicam que as cefalosporinas (ceftiofur), florfenicol e as fluorquinolonas (ciprofloxacin) são as drogas mais eficazes, fato também relatado em estudos na França, America do Norte e no Japão (KEHRENBERG et a.I., 2001; SALMON et al., 1995; YOSHIMURA et al., 2001). A resistência dos isolados frente a sulfas e ao cotrimoxazol também é previamente descrita (TANG et al., 2009).

Um isolado de gato apresentou um perfil de multirresistência bem diferente das outras cepas testadas (norfloxacina, enrofloxacina, ciprofloxacina, sulfa e cotrimoxazol), este perfil pode ser associado ao uso indiscriminado de antibióticos na prática clinica selecionando cada vez mais resistentes.

Apesar da frequência de isolamento em cães e gatos inferior ao esperado segundo a literatura consultada, os resultados obtidos no presente estudo indicam que o agente está presente em animais portadores e que estas cepas além de 
carrearem uma grande combinação de fatores de virulência também apresentam resistência a vários tipos de antimicrobianos de uso comum em medicina humana.

Os coelhos, que apresentam crescente papel como animais de companhia e também tem sua participação importante como fonte de proteína de origem animal, apresentaram uma freqüência relativamente alta de isolamento do agente $(20,7 \%)$. Sendo, que no caso dos coelhos além do potencial zoonótico do agente há uma significativa perda econômica pelas mortes e descartes de animais nos criatórios. 


\section{CONCLUSÕES}

- A freqüência de isolamento $P$. multocida no presente estudo foi maior em coelhos, seguida pelos gatos e pelos cães.

- A maior parte dos isolados das três espécies animais avaliadas pertence ao tipo capsular A e uma alta porcentagem dos mesmos não foi tipavel através da PCR.

- Através da PFGE foi possível caracterizar todas as cepas isoladas e discriminar a maior parte dos isolados de coelhos das amostras de cães e gatos.

- Todos os genes codificadores de fatores de virulência foram detectados em pelo menos um isolado, sendo que nenhum destes esteve presente em $100 \%$ das cepas avaliadas. 


\section{REFERÊNCIAS}

ASTRID, B.; LOTHAR, H. W.; HANS-J. S.; CHRISTA E. Genetic diversity of porcine Pasteurella multocida strains from the respiratory tract of healthy and disease swine. Veterinary Microbiology, v. 139, p. 97-105, 2009.

ANINA. B. J. S.; RICHARD. K. H.; PETER. K.; BOZENA. M. K. Phenotypic and genetic characterization of Pasteurella multocida and related isolates from rabbits in Switzerland. Journal Veterinary Diagnostic Investigation, v. 21, p. 793- 802, 2009.

ARUMUGAM, N. D.; AJAM, N.; BLACKALL, P. J.; ASIAH, N. M.; RAMLAN, M.; MARIA, J.; YUSLAN, S.; THONG, K. L. Capsular serotyping of Pasteurella multocida from various animal host - a comparison of phenotypic and genotypic methods.Tropical Biomedicine, v. 28, p. 55 - 63, 2011.

AVRIL, J. L.; DONNIO, P. Y. 0, POUEDRAS, P. Selective medium for Pasteurella multocida and its use to detect oropharyngeal carriage in pig breeders. Journal of Clinical Microbiology, v. 28, p. 1438-1440, 1990.

BISGAARD, M.; ABDULLAHI, M. Z.; GILMOUR, N. J. Further studies on the identification of pasteurellaceae from cattle lungs. Veterinary Record, v. 128, p. 428429, 1991

BLACKALL, P. J.; PAHOFF, J. L.; POWLES, R. Phenotypic characterization of Pasteurella multocida isolates from Australian pigs. Veterinary Microbiology, v. 57, p. 335-360, 1997.

BLACKALL, P. J.; PAHOFF, J. L.; MAKS, D.; FEGAN, N.; MORROW, C. J. Characterization of Pasteurella multocida isolates from fowl cholera outbreaks on turkey farms. Australian Veterinary Journal, v. 72, p. 135-138, 1995.

BOOM, R.; SOL, C. J. A.; SALIMANS, M. M. M.; JANSEN, C. L.; WERTHEIN-VAN DILLEN, P. M. E.; VAN DER NOORDAA, J. Rapid and simple method for purification of nucleic acids. Journal of Clinical Microbiology, v. 28, p. 495-503, 1990.

BOROWSKI, S. M. Caracterização e estudo de virulência de amostras de Pasteurella multocida isoladas de suínos no Estado do Rio Grande do Sul, Brasil. 2001 190f. Tese (Doutorado)- Faculdade de Veterinária, Universidade Federal do Rio Grande do Sul, Porto Alegre, 2001. 
BOYCE, J. D.; ADLER, B. The capsule is a virulent determinant in the pathogenesis of Pasteurella multocida M1404 (B:2). Infection and Immunity, v. 68, p. 3463-3468, 2000.

BOYCE, J. D.; CHUNG, J. Y.; ADLER, B. Pasteurella multocida capsule: composition, function and genetics. Journal of Biotechnology, v. 83, p. 153-160, 2000.

BRITO, J. R. F.; PIFFER, I .A.; WENTZ, I.; BRITO, M. A.V. P. Capsular types and toxin production by strains of Pasteurella multocida isolated from pigs in southern Brazil. Revista de Microbiologia, v. 24, p. 94-97, 1993.

CHAMPLIN, F. R.; PATTERSON, C. E.; AUSTIN, F. W.; RYALS, P. E. Derivation of extracellular polysaccharide - deficient variants from a serotype $A$ strain of Pasteurella multocida Curr Microbiology, v. 38, p. 268 - 272, 1999.

CHRISTENSEN, H.; BISGAARD, M.; ANGEN, O.; FREDERIKSEN, W.; OLSEN, J. E. Characterization of sucrose - negative Pasteurella multocida variants, including isolates from large - cat bite wounds. Journal of clinical microbiology, v. 43, p. 259- 270, 2005.

CHRISTENSEN, J. P.; BISGAARD, M. Avian pasteurellosis: taxonomy of the organisms involved and aspects of pathogenesis. Avian Pathology, v. 26, p. 461483, 1997.

COOKE, F. J.; KODJO, A.; CLUTTERBUCK, E. J.; BAMFORD, K. B. A case of Pasteurella multocida peritoneal dialysis-associated peritonitis and review of the literature. International Journal of Infectious Disease, v.8, p. 171-174, 2004.

DAVIES, R. L.; MACCORQUODALE, R.; BAILLIE, S.; CAFFREY, B. Characterization and comparison of Pasteurella multocida strains associated with porcine pneumonia and atrophic rhinitis. . Journal of medical microbiology.v. 52, p .59-67, 2003a

DAVIES, R. L.; MACCORQUODALE, R.; BAILLIE, S.; CAFFREY, B. Diversity or avian Pasteurella multocida strains based on capsular PCR typing and variation of the OmpA and $\mathrm{OmpH}$ outher membrane proteins. Veterinary Microbiology, v. 91, p. 169- 182, 2003b.

DE JONG, M. F. Progressive and non progressive atrophic rhinitis. In: STRAW, B.; D'ALLAIRE, S.; MENGELING, W.L.; TAYLOR, D. J. (Ed.) Diseases of swine. 8. ed. 1999 lowa University Press. Ames: p. 511-520.

DE JONG, M. F. Some aspects of the study of atrophic rhinitis. Tijdschr Diergeneesk, v. 105, p. 711-714, 1980. 
DOUGHTY, S. W.; RUFFOLO, C. G; ADLER, B. The type 4 fimbrial subunit gene of Pasteurella multocida. Veterinary Microbiology, v. 72, p. 79 -90, 2000.

DUGUID, J. P.; ANDERSON, E. S.; CAMPBELL, I. Fimbriae and adhesive properties in Salmonellae. Journal of Pathology and Bacteriology, v. 92, p. 107-138, 1966.

DZIVA, F.; MUHAIRWA, A. P.; BISGAARD, M.; CHRISTENSEN, H. Diagnostic and typing options for investigating diseases associated with Pasteurella multocida. Veterinary Microbiology, v. 128, p. 1-22, 2008.

EL TAYEB, A. B.; MORISHITA, T. Y.; ANGRICK, E. J. Evaluation of Pasteurella multocida isolated from rabbits by capsular typing, somatic serotyping, and restriction endonuclease analysis. Journal Veterinary Diagnosis Investigation, v. 16, p. 121125, 2004.

EWERS, C.; LUBKE-BECKER, A.; BETHE, A.; KIEBLING, S.; FILTER, M.; WIELER, L.H. Virulence genotype of Pasteurella multocida strains isolated from different hosts with various disease status. Veterinary Microbiology, v. 114, p. 304-317, 2006.

EWERS, C.; LUBKE-BECKER, A.; WIELER, L. H. Pasteurella: insights into the virulence determinants of a heterogenous bacterium. Berl. Munch. Tierartztl. Wonchenschr, v. 9-10, p. 367-386, 2004.

FREDERIKSEN, W. Ecology and significance of Pasteurellacea in man-an update. Zentralbl. Bakteriol, v. 279, p. 27-34, 1993.

GLORIOSO, J. C.; JONES, G. W.; RUSH, H. G. Adhesion of type A Pasteurella multocida to rabbit pharyngeal cells and its possible role in rabbit respiratory tract infections. Infection and Immunity, v. 35, p. 1105-1109, 1982.

GRIEGO, R. D.; ROSEN, T. M. D.; ORENGO, I. F.; WOLF, J. E. Dog, Cat and human bites: A review. Journal of the American Academy of Dermatology, v. 33, p. 1019-1029, 1995.

HAREL, J.; COTE, S.; JACQUES, M. Restriction endonuclease analysis of porcine Pasteurella multocida isolates from Quebec. Canadian Journal Veterinary Research, v. 54, p. 422-426, 1990.

HARPER, M.; BOYCE, J. D.; ADLER, B. Pasteurella multocida pathogenesis: 125 years after Pasteur. Federation of European Microbiological Societies, v. 265, p. 1-10, 2006.

HATFALUDI, T.; AL-HASANI, K.; BOYCE, J. D.; ADLER, B. Outer membrane proteins of Pasteurella multocida. . Veterinary Microbiology, v. 144, p. 1-17, 2010. 
HU, S. P.; FELICE, L. J.; SIVANANDAN, V.; MAHESWARAN, S. K. Siderophore production by Pasteurella multocida. Infection and Immunity, v. 54, p. 804-810, 1986.

HUNT, M. L.; ADLER, B.; TOWNSEND, K. M. The molecular biology of Pasteurella multocida. Veterinary Microbiology, v. 72, p. 3-25, 2000.

HUNTER, P. R.; GASTON. M. A. Numerical index of the discriminatory ability of typing systems: an application of Simpson's index of diversity. Journal of Clinical Microbiology, v. 26, p. 2465-2466, 1988.

IWAMATSU, S.; SAWADA. T. Relationship between serotypes, dermonecrotic toxin production of Pasteurella multocida isolates and pneumonic lesions of porcine lung. Japanese Journal of Veterinary Science, v. 50, p. 1200-1206, 1988.

JAMALUDIN, R.; BLACKALL, P. J.; HANSEN, M. F.; HUMPHREY, S.; STYLES, M. Phenotypic and genotypic characterization of Pasteurella multocida isolated from pigs at slaughter in New Zeland. Zeland Veterinary Journal, v. 53, p. 203-207, 2005.

JANSSEN, P.; COOPMAN, R.; HUYS, G.; SWINGS, J.; BLEEKER, M.; VOS, P.; ZABEAU, M.; KERSTERS, K. Evaluation of the DNA fingerprinting method AFLP as a new tool in bacterial taxonomy. Microbiology, v. 142, p. 1881-1993, 1996.

KAMP, E. M.; BOKKEN, G. C. A. M.; VERMEULEN, T. M. M.; DE JONG, M. F.; BUYS, H. E. C. M. ; REEK, F. H.; SMITS, M. A. A specific and sensitive PCR assay for large scale detection of toxigenic Pasteurella multocida in nasal and tonsillar swabs specimens of pigs. Journal of Veterinary Diagnostic Investigation, v. 8, p. 304-309, 1996.

KASTEN, R. W.; CARPENTER, T. E.; SNIPES, K. P.; HIRSH, D. C. Detection of Pasteurella multocida-specific DNA in turkey flocks by use of the polymerase chain reaction. Avian Diseases, v. 41 p. 676-682, 1997.

KEHRENBERG, C. G.; SCHULZE-TANZIL, J. L.; MARTEL, E.; CHASLUS-DANCLA; SCHWARZ, S. Antinicrobial resistence in Pasteurella multocida and Manheimia: epidemiology and genetic basis. Veterinary Resources. v.32, p. 323-339, 2001.

LEE, M. D.; WOOLEY, R. E.; BROWN, J.; GLISSON, J. R. A survey of potential virulence markers from avian strains of Pasteurella multocida. Veterinary Microbiology, v. 26, p. 213-225, 1991. 
LICHTENSTEIGER, C. A.; STEENBERGEN, S. M.; LEE, R. M.; POLSON, D. D.; VIMR, E. R. Direct PCR analysis for toxigenic Pasteurella multocida. Journal of Clinical Microbiology, v. 34, p. 3035-3039, 1996.

LIN, P. H.; BUSH, R. L.; ZHOU, W.; LUMSDEN, A. B. Aortic endograft infection due to Pasteurella multocida following a rabbit bite. Journal Vascular Surgery, $v .43$, p. 393-395, 2006.

LIU, W.; CHEMALY, R. F.; TUOHY, M. J.; LASALVIA, M. M.; PROCOP, G. W. Pasteurella multocida Urinary Tract Infection with Molecular Evidence of Zoonotic Transmission. Clinical Infections Diseases, v. 36, p. 58-60, 2003.

LOVE, D. N.; MALIK, R.; JACQUELINE, M. N. Bcteriological warface amongst cats: What have we learned about cat bite infection? Veterinary Microbiology, v. 74, p. 2179-2193, 2000.

LU, Y.-S.; GERRITY, L. W.; PAKES, S. P.; NIE, L. C. A monoclonal antibody against a Pasteurella multocida outer membrane protein protects rabbits and mice against pasteurellosis. Infection and Immunity, v. 59, p. 172-180, 1991.

LUBKE, A.; HARTMANN, L.; SCHRODER, W.; HELLMANN, E. Isolation and partial characterization of the major protein of the outer membrane of Pasteurella haemolytica and Pasteurella multocida. Zentralblatt fur Bakteriologie, v. 281, p. 4554, 1994.

MAROIS, C.; FABLET, C.; GAILLOT, O.; MORVAN, H.; MADEC,F.; KOBISCH, M. Molecular diversity of porcine and human isolates of Pasteurella multocida. Journal of Applied Microbiology, v.107, p. 1830 - 1836, 2009.

MCLAUCHLIN, J.; RIPABELLI, G.; BRETT, M. M.; THRELFALL, E. J. Amplified fragment length polymorphism (AFLP) analysis of Clostridium perfringens for epidemiological typing. International Journal of Food Microbiology, v. 56, p. 2128, 2000.

MOXON, E. R.; KROLL, J. S. The role of bacterial polysaccharide capsules as virulence factors. Current Topics in Microbiology and Immunology, v. 150, p. 6585, 1990.

MULLAN, P. B.; LAX, A. J. Pasteurella multocida toxin stimulates boné resorption by osteoclasts via interaction with osteoclasts via interaction with osteoblasts. Calcified Tissue International, v. 63, p. 340-345, 1998. 
MUTTERS, R.; IHM, P.; POHL, S.; FREDERICKSEN, W.; MANNHEIM, W. Reclassification of the genus Pasterurella Trevisan 1887 on the basis of deoxyribonucleic acid homology, with proposals for the new species Pasteurella dagmatis, $P$. canis, $P$. stomatis, $P$. anatis, and $P$. langaa. International Journal of Systematic Bacteriology, v. 35, p. 309-322, 1985.

MUTTERS, R.; MANNHEIM, W.; BISGAARD, M. Taxonomy of the group. In: ADLAN, C.; RUTTER, J. M. (Ed.). Pasteurella and Pasteurellosis. London: Academic Press Limited,1989. p. 3-34.

NIELSEN, J. P.; FREDERIKSEN, W. Atrophic rhinitis in pigs caused by a human isolate of toxigenic Pasteurella multocida. In: INTERNATIONAL PIG VETERINARY SOCIETY CONGRESS, 11., 1990. Proceeding: Pig Veterinary Society, 1990. p. 75.

PEDERSEN, K .B.; ELLING, F. The pathogenesis of atrophic rhinitis in pigs induced by toxigenic Pasteurella multocida. Journal of Comparative Pathology, v. 94, p. 203-214,1984.

PIFFER, I. A.; CASTRO, A. F. P. Capacidade hemaglutinante de amostras de Pasteurella multocida isoladas de suínos e sua associação com fímbria e dermotoxicidade. Arquivo Brasileiro de Medicina Veterinária e Zootecnia, v. 45, p. 443-454, 1993.

PIJOAN, C.; LASTRA, A.; RAMIREZ, C.; LEMAN, A. D. Isolation of toxigenic strains of Pasteurella multocida from lungs of pneumonic swine. Journal American Veterinary Medical Association, v. 185, p. 522-523, 1984.

PIJOAN, C. Pneumonic pasteurelosis In: STRAW, B.; D'ALLAIRE, S.; MENGELING, W. L.; TAYLOR, D. J. (Ed.) Diseases of swine. 8. ed. Ames: lowa University Press, 1999. p. 511-520.

PULLINGER, D. G.; BEVIER, T.; LAX, A. J. The Pasteurella multocida toxin is encoded within a lysogenic bacteiophage. Molecular Microbiology, v. 51, p. 255269, 2004.

RIMLER, R. B.; RHOADES, K. R. Pasteurella multocida. In: ADLAM, C.; RUTTER, J. M. (Ed.) Pasteurella e pasteurellosis. London: Academic Press, 1989. p. 85-113.

ROBERTS, I. S. The biochemistry and genetics of capsular polysaccharide production in bacteria.. Annual Review of Microbiology, v. 50, p. 285-315, 1996. 
ROUGIER, S.; GALLAND, D.; BOUCHER, S.; BOUSSARIE, D.; VALLÉ, M. Epidemiology and susceptibility of pathogenic bacteria responsible for upper respiratory tract infections in pet rabbits. Veterinary Microbiology, v. 115, p. 192198, 2006.

SALOMON, S. A. J. L.; WATTS, C. A.; CASE, L. J.; HOFFMAN, H. C.; WEGENER; YANCEY JR, R. J. Comparison of MICs of ceftiofur and other antimicrobial agents against bacterial pathogens of swine from United States, Canada and Denmark. Journal of Clinical Microbiology, v. 33, p. 2435 - 2444, 1995.

SILBERFEIN, E. J.; LIN, P. H.; BUSH, R. L.; ZHOU, W.; LUMSDEN, A. B. Aortic endograft infection due to Pasteurella multocida following a rabbit bite. Journal Vascular Surgery, v. 43, p. 393-395, 2006.

SINA, A.; JALAL, S.; MOHAMMAD, S. H. Rapid virulence typing of Pasteurella multocida by multiplex PCR. Research in Veterinary Science, v. 87, p. 355-357, 2009.

SNIPES, K. P.; GHAZIKHANIAN, G. Y.; HIRSH, D. C. Fate of Pasteurella multocida in the blood vascular system of turkeys following intravenous inoculation: comparison of an encapsulated, virulent strain with its avirulent, acapsular variant. Avian Diseases, v. 31, p. 254-259, 1986.

SHIN, E. K.; SEO, Y. S; HAN, J. H.; HAHN, T. W. Diversity of swine Bordetella bronchiseptica isolates evaluated by RAPD analysis and PFGE. J. Vet. Sci.,v 8, n.1, p.65-73, 2007.

STEEN, J. A.; STEEN, J. A.; HARRISON,P.; SEEMANN, T.; WILKIE, I.; HARPER, M.; ADLER, B.; BOYCE, J. D. Fis Is Essential for capsule production in Pasteurella multocida and regulates expression of other important virulence factors. PLoS Pathogens, v. 6, p. 1 - 14, 2010.

STERNER-KOCK, A.; LANSKE, B.; UBERSCHAR, S.; ATKINSON, M. J. Efects of the Pasteurella multocidab toxin on osteoblastic cells in vitro. Veterinary pathology, v. 32, p. 274-279, 1995.

TALAN, D. A.; CITRON, D. M.; ABRAHAMIAN, F. M.; MORAN, G. j.; GOLDSTEIN, E. J. C. Bacteriologic analysis of infected dogs and cats bites. New England Journal Medicine, v. 340, p. 85- 92, 1999. 
TANG, X.; ZHAO, Z.; HU, J.; WU, B.; CAI, X.; HE, Q.; CHEN, H. Isolation, Antimicrobial Resistence, and Virulence Genes of Pasteurella multocida Strains from Swine in China. Journal of Clinical Microbiology, v.april, p. 951-958, 2009.

TILLEY, P. L.; SMITH, W. K. F. Consulta veterinária em 5 minutos espécies canina e felina, $2^{a}$ ed., Editora Manole, 2003.

TOWSEND, K. M.; FROST, A. J.; LEE, C.W.; PAPADIMITRIOU, J. M.; DAWKINS, H. J. S. Development of PCR assays for species- and type-specific identification of Pasteurella multocida isolates. Journal of Clinical Microbiology, v. 36, p. 10961100, 1998.

TRIGO, E.; PIJOAN, C. Presence of pili in Pasteurella multocida strains associated with atrophic rhinitis. Veterinary Record, v. 122, p. 19, 1988.

TRUSCOTT, W. M.; HIRSH, D. C. Demonstration of an outer membrane protein with antiphagocytic activity from Pasteurella multocida of avian origin. Infection and Immunity, v.56, p. 1538-1544, 1988.

TURNQUIST, S. E. Etiology and diagnosis of progressive atrophic rhinitis. Swine Health and Production, v. 3, p. 168-170, 1995.

ZHAO, G.; PIJOAN, C.; CHOI, K.; MAHESWARAN, K.; TRIGO, E. Expression of iron-regulated outer membrane proteins by porcine strains of Pasteurella multocida. Canadian Journal of Veterinary Research, v. 59, p. 46-50, 1995.

VELAPPAN, N.; SNODGRASS, J. L.; HAKOVIRTA, J. R.; MARRONE, B. L.; BURDE, S. Rapid identification of pathogenic bacteria by single-enzyme amplified fragment length polymorphism analysis. Diagnostic Microbiology Infection Diseases, v. 39, p. 77-83, 2001

YOSHIMURA, H. M.; ISHIMURA, Y. S. E.; KOJIMA, A. Antimicrobial susceptibility of Pasteurella multocida isolated from cattle and pigs. v. 48, p. 555- 560. 